\title{
Management of HIV-associated tuberculosis in resource-limited settings: a state-of-the-art review
}

\author{
Stephen D Lawn ${ }^{1,2,3^{*}}$, Graeme Meintjes ${ }^{3,4}$, Helen Mclleron ${ }^{5}$, Anthony D Harries ${ }^{1,6}$ and Robin Wood ${ }^{2,3}$
}

\begin{abstract}
The HIV-associated tuberculosis (TB) epidemic remains a huge challenge to public health in resource-limited settings. Reducing the nearly 0.5 million deaths that result each year has been identified as a key priority. Major progress has been made over the past 10 years in defining appropriate strategies and policy guidelines for early diagnosis and effective case management. Ascertainment of cases has been improved through a twofold strategy of provider-initiated HIV testing and counseling in TB patients and intensified TB case finding among those living with HIV. Outcomes of rifampicin-based TB treatment are greatly enhanced by concurrent co-trimoxazole prophylaxis and antiretroviral therapy (ART). ART reduces mortality across a spectrum of CD4 counts and randomized controlled trials have defined the optimum time to start ART. Good outcomes can be achieved when combining TB treatment with first-line ART, but use with second-line ART remains challenging due to pharmacokinetic drug interactions and cotoxicity. We review the frequency and spectrum of adverse drug reactions and immune reconstitution inflammatory syndrome (IRIS) resulting from combined treatment, and highlight the challenges of managing HIV-associated drug-resistant TB.
\end{abstract}

\section{Introduction}

The global epidemics of HIV/AIDS and tuberculosis (TB) both remain huge challenges to international public health, causing illness and death in millions of people worldwide each year (Table 1) [1]. TB is the most important AIDSrelated opportunistic disease globally and is the leading cause of HIV/AIDS-related mortality, accounting for an estimated $25 \%$ of such deaths [2,3]. Sub-Saharan Africa suffers disproportionately, with $79 \%$ of global cases of HIVassociated TB [1]. In the countries of southern and eastern Africa where HIV prevalence is highest, the impact of HIV has severely undermined TB control over the past 20 years [4]. The global co-epidemic has been further compounded in recent years by the emergence of the growing challenge of multi-drug resistant TB (MDR-TB) [5,6].

The World Health Organization (WHO) DOTS (directly observed treatment, short-course) TB control strategy used in isolation provides far from optimum case

\footnotetext{
* Correspondence: stephen.lawn@lshtm.ac.uk

'Department of Clinical Research, Faculty of Infectious and Tropical Diseases, London School of Hygiene and Tropical Medicine, Keppel Street, London WC1E 7HT, UK

${ }^{2}$ The Desmond Tutu HIV Centre, Institute for Infectious Disease and Molecular Medicine, Faculty of Health Sciences, University of Cape Town, Cape Town, South Africa

Full list of author information is available at the end of the article
}

management for individual patients with HIV-associated $\mathrm{TB}$ and it has failed to control TB at a population level in settings with high HIV prevalence [2,7]. Comprehensive packages of additional interventions are needed to address the consequences of HIV in TB patients and to reduce the burden of TB in those living with HIV infection [8]. An interim policy on collaborative TB/HIV activities was first published by WHO in 2004 [9] and approximately 1.3 million lives are estimated to have been saved by these interventions by 2011 [1]. An updated policy (Table 2) [10] published in 2012 provides the overall policy framework for addressing HIV-associated TB and specific recommendations on management of HIV, TB and multidrugresistant (MDR)-TB are provided by individual guideline documents [11-13] (Table 3).

This article provides an up-to-date review of the current medical management of adult patients with HIV-associated TB. We review case ascertainment as the critical first step and then how clinical outcomes can be optimized by provision of effective TB treatment, use of concurrent ART, prevention of HIV-related comorbidities and management of drug cotoxicity and immune reconstitution inflammatory syndrome (IRIS). We also describe the management of HIV-associated MDR-TB. However, the management of children, models of integrated TB and 
Table 1 Burden of HIV infection, tuberculosis (TB) and HIV-associated TB globally and in sub-Saharan Africa

\begin{tabular}{lcc}
\hline Disease & Global burden & Burden in sub-Saharan Africa: (\% of global burden) \\
\hline HIV/AIDS: & & $23,500,000(69 \%)$ \\
No. of people living with HIV infection & $34,200,000$ & $1,200,000(71 \%)$ \\
HIV/AIDS-related deaths & $1,700,000$ & $2,300,000(26 \%)$ \\
Tuberculosis: & & $220,000(22 \%)$ \\
No. of incident cases of TB & $8,700,000$ & $45,000(15 \%)$ \\
TB deaths (excluding HIV) & 990,000 & $870,000(79 \%)$ \\
Incident cases of multidrug-resistant TB & 310,000 & $300,000(70 \%)$ \\
HIV-associated tuberculosis: & & $1,100,000$ \\
No. of incident cases & 430,000 & \\
No. of HIV-associated TB deaths &
\end{tabular}

Data from $[1,3]$. Incident disease and deaths represent annual disease burden.

HIV care delivery and prevention of TB in people living with HIV using ART and isoniazid preventive therapy lie outside the scope of this review.

\section{Diagnosis of HIV-associated TB}

The prerequisite for optimum management of HIVassociated TB is early and accurate diagnosis and, for many years, this has been a key obstacle. Case ascertainment can be greatly improved by high rates of qualityassured HIV testing among those being investigated for $\mathrm{TB}$ as well as high rates of screening for TB in those living with HIV.

\section{Screening for TB in those living with HIV infection}

In high burden settings, much prevalent TB disease remains 'below the radar' in those living with HIV. Postmortem studies conducted in hospitals across sub-Saharan
Africa over the past 20 years have repeatedly shown that between $30 \%$ and $50 \%$ of HIV-infected adult inpatients who die have postmortem evidence of TB, much of which was neither clinically suspected nor diagnosed before death [14-17]. These studies have highlighted the abject failure of the diagnostic process and the low sensitivity of diagnostic tools available [18]. In the absence of more sensitive means of diagnosis, management algorithms for suspected sputum smear-negative disease were developed [19-21] and studies of empirical TB treatment for certain high risk patient groups with advanced immunodeficiency are being conducted [22].

However, in recent years there have been significant advances in screening and diagnosis. Traditional symptom screening for pulmonary TB based on chronic cough has low sensitivity for HIV-associated TB [23,24]. A new WHO symptom screening tool for HIV-associated TB

Table 2 World Health Organization (WHO)-recommended collaborative tuberculosis (TB)/HIV activities (adapted from [10])

\begin{tabular}{|c|c|}
\hline Key area & Points of action \\
\hline \multirow{4}{*}{$\begin{array}{l}\text { Establish and strengthen the mechanisms for } \\
\text { delivering integrated TB and HIV services }\end{array}$} & Set up and strengthen a coordinating body for collaborative TB/HIV activities \\
\hline & $\begin{array}{l}\text { Determine the HIV prevalence among TB patients and the TB prevalence among } \\
\text { HIV patients }\end{array}$ \\
\hline & Carry out joint TB/HIV planning to integrate the delivery of TB and HIV services \\
\hline & Monitor and evaluate collaborative TB/HIV activities \\
\hline \multirow{3}{*}{$\begin{array}{l}\text { Reduce the burden of TB in people living with } \\
\text { HIV (early ART plus the three Is) }\end{array}$} & Intensify TB case finding and ensure high quality TB treatment \\
\hline & $\begin{array}{l}\text { Initiate TB prevention using isoniazid preventive therapy and early antiretroviral } \\
\text { therapy (ART) }\end{array}$ \\
\hline & Ensure control of TB infection in healthcare facilities and congregate settings \\
\hline \multirow{5}{*}{$\begin{array}{l}\text { Reduce the burden of HIV in patients with diagnosed } \\
\text { TB and those under investigation for TB }\end{array}$} & Provide HIV testing and counseling to both groups of patients \\
\hline & Provide HIV preventive interventions to both groups of patients \\
\hline & Provide co-trimoxazole preventive therapy for TB patients living with HIV \\
\hline & $\begin{array}{l}\text { Provide HIV prevention interventions, treatment and care for TB patients living } \\
\text { with HIV }\end{array}$ \\
\hline & Provide antiretroviral therapy for TB patients living with HIV \\
\hline
\end{tabular}


Table 3 World Health Organization (WHO) policy guidelines on collaborative tuberculosis (TB)/HIV activities and the management of HIV infection, TB and multidrug-resistant TB (MDR-TB)

\begin{tabular}{|c|c|c|}
\hline Guidelines/year & Details & Reference \\
\hline Guidelines for collaborative TB/HIV activities (2012) & $\begin{array}{l}\text { World Health Organization. WHO policy on collaborative TB/HIV activities. } \\
\text { Guidelines for national programmes and stakeholders. 2012. World Health } \\
\text { Organization, Geneva. WHO/HTM/TB/2012.1. http://whqlibdoc.who.int/ } \\
\text { publications/2012/9789241503006_eng.pdf }\end{array}$ & {$[10]$} \\
\hline Antiretroviral treatment guidelines (2013) & $\begin{array}{l}\text { World Health Organization. Consolidated guidelines on the use of antiretroviral } \\
\text { drugs for treating and preventing HIV infection. Recommendations for a public } \\
\text { health approach, June 2013. WHO, Geneva. Accessible at: http://apps.who. } \\
\text { int/iris/bitstream/10665/85321/1/9789241505727_eng.pdf. }\end{array}$ & {$[11]$} \\
\hline Tuberculosis treatment guidelines (2010) & $\begin{array}{l}\text { World Health Organization. Treatment of tuberculosis: guidelines - fourth edition. } \\
\text { World Health Organization, Geneva, 2010. WHO/HTM/TB/2009.420 Accessible } \\
\text { at: http://whqlibdoc.who.int/publications/2010/9789241547833_eng.pdf }\end{array}$ & {$[12]$} \\
\hline Drug-resistant TB treatment guidelines (2011) & $\begin{array}{l}\text { World Health Organization. Guidelines for the management of drug-resistant } \\
\text { tuberculosis: } 2011 \text { update. WHO, Geneva. WHO/HTM/TB/2011.6. Accessible at: } \\
\text { http://whqlibdoc.who.int/publications/2011/9789241501583_eng.pdf. }\end{array}$ & {$[13]$} \\
\hline
\end{tabular}

(one or more of the following symptoms: cough, fever, weight loss or night sweats, each of any magnitude or duration) has much higher sensitivity and is recommended for routine screening of those in HIV care at each visit [25]. However, in view of its low specificity, further research is needed to define which of the large number of patients with a positive screen should be prioritized for subsequent microbiological testing of clinical samples.

New diagnostic tools have also increased our capacity for microbiological diagnosis. This includes the Xpert MTB/RIF assay, which was endorsed by WHO in 2010. A single test is able to detect all sputum smear-positive disease, approximately $70 \%$ of smear-negative pulmonary disease and provides rapid simultaneous screening for RIF resistance [26]. In addition, this assay can be used to test a wide range of extrapulmonary sample types [26,27]. The Xpert MTB/RIF assay has been incorporated into the national guidelines of many high burden countries. In South Africa, which alone accounts for approximately $30 \%$ of the global burden of HIV-associated TB, sputum smear microscopy has now been replaced by Xpert MTB/RIF as the initial diagnostic test for TB [26].

Determine TB-LAM is a low-cost, point-of-care lateralflow ('strip test') assay that diagnoses TB through detection in urine of lipoarabinomannan (LAM): a lipopolysaccharide component of the M. tuberculosis cell wall [28]. It has high specificity whereas sensitivity is very strongly CD4 count dependent, at best detecting approximately twothirds of cases in those with CD 4 counts $<50$ cells $/ \mu \mathrm{l}$ [28-31]. This assay therefore allows rapid ( $<30$ minutes) bedside diagnosis among those who have the highest mortality risk [32]. The growing evidence base on this assay will be reviewed by WHO in 2014. Its role is likely to be as an add-on test within the diagnostic algorithm to permit point-of-care diagnosis and immediate TB treatment among patients with advanced immunodeficiency
(CD4 counts $<200$ cells/ $\mu$ l) following admission to hospital or enrolling in ART clinics [28,31].

\section{Screening for HIV in those with TB or possible TB}

A major step forward in improving HIV testing rates in patients with TB was the switch from voluntary counseling and testing (VCT) to provider-initiated testing and counseling (PITC) in 2007 [33]. With PITC, all patients undergo routine testing unless they specifically opt out. Testing has increased globally from $3.1 \%$ in 2004 to $40 \%$ of notified TB cases in 2011, but falls well short of the goal of universal testing [1]. Testing rates have reached $69 \%$ in Africa, $>50 \%$ in the Americas and $32 \%$ in South-East Asia. In African countries, the proportion of TB patients testing positive is $46 \%$ overall (range, $8 \%$ to $77 \%$ ) and exceeds $50 \%$ in ten counties in the south and east of the continent [1]. A further significant policy change has been to expand PITC to include all patients being investigated for TB regardless of whether or not TB is diagnosed [10,12]. This change resulted from the observed high HIV prevalence and mortality among those presenting for investigation of possible TB even when this diagnosis was subsequently excluded [34]. It is critical, however, that improved testing rates are accompanied by improvement in the delivery of appropriate management.

\section{Optimized TB treatment}

The first priority for patients with HIV-associated TB is to immediately start effective TB treatment using a regimen containing RIF throughout [12,35]. A systematic review found that the incidence of relapse and/or failure among patients treated with intermittent (thrice weekly) TB therapy throughout was two to three times higher than that in patients who received a daily intensive phase [36]. Thus, the recommended optimum standard regimen is 2 months of rifampicin, isoniazid, pyrazinamide and ethambutol 
followed by 4 months of rifampicin and isoniazid (2HRZE/ 4HR), with therapy administered daily throughout [12]. Where this is not possible, an acceptable alternative is to use a thrice-weekly continuation phase. Treatment outcomes are worse for those with isoniazid monoresistance $[36,37]$ and, thus, in settings with high prevalence of isoniazid monoresistance, 2HRZE/4HRE is the recommended first-line regimen [12]. Drug susceptibility testing is recommended to guide treatment in patients who have previously been treated for TB, although ideally all patients with TB should have drug susceptibility testing. Where the Xpert MTB/RIF assay is being rolled out as the primary TB diagnostic test, RIF resistance screening is now integral to the initial diagnostic process [26].

After several decades with no new advances in TB treatment, there are now some promising developments. For example, several large-scale phase III randomized controlled trials (including the ReMOX, Oflotub and RIFAQUIN studies) are evaluating whether incorporation of a newer fluoroquinolone into treatment regimens can be used to shorten treatment for drug susceptible TB [38]. The first of these to report, the RIFAQUIN study, found treatment shortening was associated with a higher rate of adverse outcomes including failure, relapse and death [39]. However, none of these studies have been designed to specifically address this question in HIV-infected clinical populations. There is also a growing developmental pipeline of new TB drugs, although these are most likely to be used in the treatment of MDR-TB, at least initially [38].

\section{Co-trimoxazole preventive therapy}

Co-trimoxazole (trimethoprim sulfamethoxazole) is a lowcost, widely available and relatively safe antibiotic that reduces morbidity and mortality in people living with HIV due to prophylactic activity against a range of pathogens, including those causing bacterial sepsis, pneumocystis pneumonia, cerebral toxoplasmosis and malaria. Both observational and randomized controlled trials conducted in sub-Saharan Africa have shown that this simple intervention is associated with a substantial reduction in mortality among patients with HIV-associated TB (range, 19\% to 46\%) [40-44] (Table 4). This beneficial effect was observed in a range of settings with high or low rates of bacterial resistance to the drug and is additive in reducing early mortality when combined with ART [45].

Routine administration of co-trimoxazole to patients with HIV-associated TB is recommended (480 $\mathrm{mg}$ twice per day or $960 \mathrm{mg}$ once per day) [10-12]. Implementation of this simple, life-saving intervention has steadily increased from a negligible proportion in 2004 to $79 \%$ of all notified TB cases with a positive HIV test in 2011 (79\% of those in the African region and $89 \%$ of those in the South-East Asian region) [1]. Coverage needs to increase to the $100 \%$ target set in the Global
Plan to Stop TB, 2011-2015 [46]. Evidence is unclear as to whether co-trimoxazole should be continued indefinitely or might be discontinued once the CD4 cell count has reached a threshold of either 200 or 350 cells/ $\mu \mathrm{l}$ [11]. The potential benefits of ongoing therapy may vary according to local factors such as the safety of the water supply, the presence of malaria and the local spectrum of opportunistic pathogens.

\section{Antiretroviral treatment}

In observational cohort studies, concurrent ART reduces mortality risk by $64 \%$ to $95 \%$ in patients receiving treatment for HIV-associated TB [47]. In the South African Starting Antiretroviral Therapy at Three Points in Tuberculosis Therapy (SAPIT) randomized trial, receipt of concurrent ART was associated with survival benefit among those with CD4 cell counts of $<200$ cells $/ \mu$ l and 200 to 500 cells $/ \mu$ l [48]. Recommended first-line ART regimens for use with TB treatment are based on nonnucleoside reverse transcriptase inhibitors (NNRTI), with efavirenz (EFV) as the preferred choice and nevirapine (NVP) as an alternative. While first-line regimen choices are well established, second-line ART remains problematic. The recommended regimens and their pharmacokinetic interactions with $\mathrm{TB}$ treatment are shown in Table 5 and the hiv-druginteractions.org website provides a useful up-to-date source of information on interactions (see [49]). Combining the multidrug regimens used to treat TB and HIV is complicated not only by high pill burden and increased risks of drug-drug interactions, but also by cotoxicity and immune reconstitution inflammatory syndrome (IRIS).

\section{Pharmacokinetic interactions with first-line ART}

Although RIF induces the expression of cytochrome P450 2B6 (CYP2B6), which comprises the main metabolic pathway for EFV, studies have failed to demonstrate significantly reduced concentrations of EFV with concomitant RIF-based TB treatment [50-53]. This is consistent with the observed virological responses which are excellent in patients receiving RIF-based TB treatment treated with standard $600 \mathrm{mg}$ daily doses of EFV [54-57] and were better than those in TB patients randomized to NVP-based ART in the recent CARINEMO trial [56]. Similarly, lowering the dose of EFV to $400 \mathrm{mg}$ daily in the ENCORE1 trial did not compromise outcomes in non-TB patients [58]. Thus, although the US Federal Drug Administration (FDA) [59] recommends that the dose of EFV during RIF treatment is increased in adults weighing more than $50 \mathrm{~kg}$, this is not supported by studies in TB patients [53] and is not recommended by the WHO for resource-limited settings.

Conversely, however, among patients with a slow CYP2B6 metabolizer genotype, EFV concentrations are 
Table 4 Impact of co-trimoxazole prophylaxis on mortality among predominately adult patients with HIV-associated tuberculosis (TB)

\begin{tabular}{|c|c|c|c|c|c|c|}
\hline Study & Year of publication & Study design & Country & $\begin{array}{l}\text { Level of bacterial } \\
\text { resistance to } \\
\text { co-trimoxazole }\end{array}$ & $\begin{array}{l}\text { No. of study } \\
\text { participants }\end{array}$ & $\begin{array}{l}\text { Mortality } \\
\text { reduction }\end{array}$ \\
\hline Wiktor et al. [40] & 1999 & Randomized controlled trial & Cote D'Ivoire & Low & 771 & $46 \%$ \\
\hline Zachariah et al. [41] & 2003 & $\begin{array}{l}\text { Cohort study ('before' and 'after' } \\
\text { study with historical controls) }\end{array}$ & Malawi (north) & High & 1,986 & $19 \%$ \\
\hline Mwaungulu et al. [42] & 2004 & $\begin{array}{l}\text { Cohort study ('before' and 'after' } \\
\text { study with historical controls) }\end{array}$ & Malawi (south) & High & 717 & $22 \%$ \\
\hline Grimwade et al. [43] & 2005 & $\begin{array}{l}\text { Cohort study ('before' and 'after' } \\
\text { study with historical controls) }\end{array}$ & South Africa & High & 3,325 & $29 \%$ \\
\hline Nunn et al. [44] & 2008 & Randomized controlled trial & Zambia & High & 1,003 & $21 \%$ \\
\hline
\end{tabular}

increased during TB treatment, possibly due to inhibition by INH of accessory pathways metabolizing EFV $[60,61]$. This genotype is relatively common in Africa, South-East Asia, and the Caribbean [50-52,62,63]. Whether EFV-induced central nervous system (CNS) adverse effects are more frequent during TB treatment or isoniazid preventive therapy in patients with this genotype needs to be evaluated.

NVP is a reasonably safe, acceptable alternative for TB patients unable to tolerate EFV. Through induction of the expression of CYP2B6, RIF treatment reduces NVP concentrations by an average of approximately $40 \%$ and
NVP-based ART remains inferior to EFV-based regimens in TB patients [56]. During the 14-day lead-in phase of NVP dosing, plasma drug concentrations are very low in patients receiving RIF, potentially predisposing to the development of viral resistance mutations and contributing to an increased risk of virological failure [54]. The CARENIMO trial recently found that NVP was well tolerated when introduced at full doses (200 mg twice a day) in patients with CD4 cell counts $<250$ cells $/ \mathrm{mm}^{3}$ receiving RIF [56]. The use of a dose escalation lead-in phase to avoid toxicity in patients receiving RIF is therefore not recommended.

\section{Table 5 Approaches to cotreatment for HIV-infected patients with rifampicin-susceptible tuberculosis}

\begin{tabular}{ll}
\hline Combined regimens & Treatment recommendations \\
\hline Efavirenz + rifampicin-based & No dose adjustments TDF + 3TC/FTC + EFV \\
TB treatment & (WHO-recommended optimum regimen) \\
& AZT $+3 T C+$ EFV (alternative WHO regimen) \\
& \\
Nevirapine + rifampicin-based & Omit 14 day lead-in phase of once daily dose of \\
TB treatment & NVP TDF $+3 T C / F T C+$ NVP (alternative WHO regimen) \\
& AZT $+3 T C+$ NVP (alternative WHO regimen)
\end{tabular}

Lopinavir/ritonavir + rifampicinbased TB treatment

$\mathrm{PI}$ /ritonavir + rifabutin-based TB treatment
Double dose lopinavir/ritonavir (800/200 mg 12 hourly) Or superboost lopinavir (lopinavir/ ritonavir 400/400 mg 12 hourly) Monitor alanine transaminase (ALT) closely.

Reduce rifabutin dose to $150 \mathrm{mg}$ daily or thrice weekly. Monitor closely for rifabutin toxicity.

Drug-drug interactions
Rifampicin induces CYP2B6 but inhibition of CYP2A6 by
isoniazid might account for increased efavirenz
concentrations during TB treatment in those patients with
slow CYP2B6 metabolizer genotype

Rifampicin induces CYP2B6 and CYP3A4. Although TB treatment reduces nevirapine concentrations, toxicity concerns curtail increasing the dose and outcomes are acceptable (but inferior to EFV) on standard doses.

Rifampicin induces CYP3A4, p-glycoprotein and OATP1B1. Ritonavir counteracts this effect and adjusted doses of ritonavir or lopinavir/ritonavir are used to compensate, but lopinavir concentrations may be more variable. Increased risk of hepatotoxicity, and gastrointestinal side effects.

Ritonavir-boosted PIs markedly increase rifabutin concentrations and reduce its clearance necessitating reduction in the dose of rifabutin by $50 \%$ to $75 \%$. Toxicity (neutropenia, uveitis, hepatoxicity, rash, gastrointestinal symptoms) and suboptimal rifamycin exposures with reduced dose are concerns.

Triple nucleoside/tide regimens may perform adequately in patients with viral suppression who have not failed a first line regimen, and provide alternative ART regimens in patients with contraindications to efavirenz or nevirapine, wehre other options are unavailable. TB treatment has minimal effect on tenofovir concentrations. Although rifampicin induces the enzymes responsible for glucuronidation of abacavir and zidovudine, this effect is not thought to be clinically important. 
Triple nucleoside/tide regimens are less effective than NNRTI-based or PI-based regimens particularly in patients with baseline viral loads $>100,000$ copies/ml [64]. However, small uncontrolled studies suggest they may provide an acceptable regimen for TB patients who have not failed an ART regimen $[65,66]$ even though the concentrations of abacavir and zidovudine may be reduced by concomitant RIF. This therefore provides an alternative option for those in whom EFV and NVP are contraindicated and integrase inhibitors unavailable.

\section{Pharmacokinetic interactions with second-line ART}

With increasing numbers of patients switching to protease inhibitor (PI)-based second-line ART regimens, defining safe and effective approaches to concurrent TB treatment is an urgent challenge. The pharmacokinetic interactions between rifamycins and PIs are extensive. RIF reduces concentrations of ritonavir-boosted PIs by $75 \%$ to $90 \%$ [67]. Conversely, through potent inhibition of CYP3A4 and p-glycoprotein, high-dose ritonavir offsets the effect of RIF-mediated induction such that 'superboosting' of lopinavir or saquinavir (lopinavir/ritonavir $400 \mathrm{mg} / 400 \mathrm{mg}$ or saquinavir/ritonavir $400 \mathrm{mg} /$ $400 \mathrm{mg}$, twice daily) preserves plasma concentrations of the PI [68-70]. Adequate plasma concentrations of lopinavir are also achieved in adults by doubling the dose of lopinavir/ritonavir in the tablet formulation (to 800/200 mg twice daily); this is the simplest approach, especially in settings where the separate ritonavir is not available [71]. Although these approaches are associated with high rates of hepatotoxicity in studies of healthy volunteers, these seem to be much safer in HIV infected patients [71-76]. Nevertheless, hepatotoxicity, gastrointestinal side effects and poor tolerability are problematic and treatment discontinuation rates of up to nearly $50 \%$ have been reported $[74,75]$.

Rifabutin is an alternative rifamycin to RIF, but data on its use in TB patients receiving ritonavir-boosted PIs are limited. Studies of healthy volunteers show that ritonavir-boosted PIs increase the concentrations of rifabutin approximately fourfold and the concentrations of the active metabolite to an even greater extent. Thus, the dose of rifabutin needs to be reduced. Thrice weekly $150 \mathrm{mg}$ doses of rifabutin in combination with standard doses of lopinavir/ritonavir may be reasonably tolerated $[77,78]$. However, contrary to expectations based on pharmacokinetic data from healthy volunteers, small studies in coinfected patients have found that rifabutin $150 \mathrm{mg}$ used thrice weekly in combination with lopinavir/ritonavir resulted in low rifabutin concentrations [79-82]. Such levels would be conducive to acquisition of rifamycin resistance in patients with severe immunosuppression $[79,83]$ as has been observed with twice weekly doses [84]. Thus, recent US national guidelines recommend a daily $150 \mathrm{mg}$ dose of rifabutin for patients on ritonavir-boosted PIs [85].

There is extremely limited information about the safety or efficacy using rifabutin with PIs and this may vary between populations due to differential increases in rifabutin concentrations. Severe neutropenia and uveitis occur relatively frequently in patients with increased exposures $[81,86]$ and hepatitis, gastrointestinal symptoms, rashes and anemia are also important safety concerns $[87,88]$. While rifabutin is becoming more widely available and affordable, it is not an ideal solution for high burden settings where limited patient monitoring is available and fixed dose drug formulations are preferred. Thus, there is an urgent need for research to define the optimum approaches for the cotreatment of patients with TB who have failed first-line ART, including the use of newer agents.

\section{Pharmacokinetic interactions with newer ART drugs}

Ritonavir-boosted darunavir has a favorable safety and tolerability compared to lopinavir/ritonavir and promising efficacy, especially in treatment of ART-experienced patients. A pharmacokinetic study in healthy volunteers suggests that it could be used in standard doses with rifabutin $150 \mathrm{mg}$ thrice weekly, but the drug-drug interactions with RIF have not been studied. Integrase inhibitors have potent antiviral activity and are well tolerated, but any future role in ART programs in low-resource settings is at present undefined. However, initial data on use with TB treatment show promise. Pharmacokinetic studies suggest that doubling the dose of raltegravir to $800 \mathrm{mg}$ twice daily compensates for the effect of RIF on overall exposure $[89,90]$ and this approach seems to be well tolerated and effective in patients with HIVassociated TB [91]. However, preliminary results of the REFLATE TB study suggest that such dose adjustment may not even be necessary as virological responses were similar in ART-naive TB patients receiving RIF who were randomized to receive $400 \mathrm{mg}$ or $800 \mathrm{mg}$ of raltegravir twice daily or EFV daily [92]. Similar to raltegravir, a pharmacokinetic study of dolutegravir in healthy volunteers suggests that the effect of RIF on antiretroviral therapy can be overcome by increasing the daily $50 \mathrm{mg}$ dose of dolutegravir to $50 \mathrm{mg}$ twice daily and that dose adjustment may not be necessary with rifabutin [93].

\section{Timing of ART initiation during TB treatment}

The optimum time to start ART in patients with HIVassociated TB is subject to a complex series of competing risks [94] and must balance the high risk of morbidity and mortality in patients with very low CD4 cell counts and severe disease with the potential occurrence of additive toxicities and immune reconstitution inflammatory syndrome (IRIS). Results of large randomized 
strategy trials are now available to inform guidelines (Table 6) [48,55,95-98]. Patients with baseline CD4 counts of $<200$ and 200 to 500 cells $/ \mu$ l have improved survival benefit from coadministered ART [48] and WHO recommends that ART be given to all patients concurrently with TB treatment regardless of the CD4 count. Trial data also demonstrated that mortality was reduced in those with the most severe immunodeficiency (CD4 cell counts $<50$ cells/ $\mu$ l) if they stated ART within the first 2 weeks of TB treatment [11]. For patients with less severe immunosuppression ( $\mathrm{CD} 4$ counts $>50$ cells $/ \mu \mathrm{l})$, data suggested that ART might be deferred until completion of the intensive phase of TB treatment without compromising survival but reducing the risk of morbidity from TB-IRIS $[55,96]$.

WHO guidelines reflect these findings, recommending that TB treatment should be started first and followed by ART as soon as possible within the first 8 weeks of treatment but within the first 2 weeks for those with profound immunosuppression (CD4 count $<50$ cells/ $\mu \mathrm{l}$ ) [11]. However, CD4 count measurements may either be unavailable or be inaccurate in some settings. In addition, within different CD4 count categories, there is great diversity in severity of disease and mortality risk. Thus, where feasible, decisions on timing for individual patients might also be further informed by taking into account clinical criteria such as body mass index, Karnofsky score, severity of anemia and extent of TB. Moreover, national guidelines might best be appropriately tailored for operational simplicity. One possible option, for example, might be to start ART in all patients after 2 weeks of TB treatment, accepting lower risk of mortality but higher risk of TB IRIS.

Patients with HIV-associated TB meningitis represent an important exception. A randomized trial from Viet Nam found no survival benefit from early ART in patients with TB meningitis [97], reflecting the awful prognosis (mortality approximately 60\%) of these patients with advanced disease and the dire consequences of TBIRIS within the confined space of the CNS [99]. Further studies are required in different geographical settings to better define appropriate management of these patients.

\section{Adverse drug reactions and management}

Antituberculosis and antiretroviral drugs have overlapping toxicity profiles that include drug-induced liver injury (DILI), cutaneous reactions, renal impairment, neuropathy and neuropsychiatric adverse effects (Table 7). These complicate management in a substantial minority of patients.

In patients without coinfection, DILI (variably defined as, for example, an elevation of alanine aminotransferase to $>3$ or $>5$ times the upper limit of the normal range) occurs in $5 \%$ to $33 \%$ of those receiving $\mathrm{TB}$ treatment [100] and in $5 \%$ to $11 \%$ of those receiving currently recommended ART regimens [101,102]. HIV infection itself has been identified as a risk factor for DILI in patients receiving TB treatment in some $[103,104]$ but not all studies [105-108]. Of the currently used ART drugs, NVP is associated with highest risk of DILI; however, EFV and PIs are also recognized causes.

Concurrent TB treatment in patients receiving NNRTIbased ART has been associated with an increased risk of DILI in some [109-111] but not all [54] studies. In one of these, the absolute risk of severe hepatotoxicity in patients receiving EFV-based ART was low, but the risk associated with concurrent TB treatment exceeded that associated with positive hepatitis B surface antigen status [109]. Importantly, a randomized trial of NVP-based versus EFVbased ART in patients receiving TB treatment reported more treatment discontinuations related to DILI in the NVP arm (4 vs 0\%) [56].

Development of DILI significantly complicates management of HIV-associated TB. Elevation of alanine transaminase (ALT) concentrations $>3$ to 5 times the upper limit of normal especially when accompanied by symptoms or jaundice requires that all potentially hepatotoxic medication is interrupted until derangements of liver function tests resolve. Thereafter, rechallenge of first-line TB medication should be considered followed by ART, although rechallenge is generally not undertaken if there was liver failure. Rechallenge strategies have not been studied in randomized trials in HIVinfected patients. However, in the largest randomized trial of TB without HIV coinfection, approximately $90 \%$ of patients were rechallenged with their first-line TB drugs without recurrence [112]. Risk of recurrence was not related to whether the four first-line TB drugs were reintroduced sequentially or concurrently. Further studies are needed to define the optimum rechallenge strategy in coinfected patients in whom both TB treatment and ART require reintroduction. Until further evidence emerges, the American Thoracic Society recommends that RIF can be reintroduced in coinfected patients once the ALT is less than two times the upper limit of normal followed by reintroduction of INH with monitoring of liver function [100]. However, they also suggest that pyrazinamide is not reintroduced.

While some cohort studies have suggested low morbidity and mortality in HIV-infected patients with DILI [109], mortality is substantial among those requiring hospital admission. In a South African study, mortality was 35\% among patients admitted to hospital with DILI during TB treatment, ART or concurrent therapy [113]. Reasons for these deaths were sepsis and liver failure, although interruption of required TB treatment and ART are likely to have played a role.

TB treatment is associated with a spectrum of cutaneous adverse reactions including morbiliform rashes, 
Table 6 Randomized controlled studies of the timing of starting antiretroviral therapy (ART) during tuberculosis (TB) treatment

\begin{tabular}{|c|c|c|c|c|c|c|c|c|c|c|}
\hline \multirow[t]{2}{*}{ Study } & \multicolumn{4}{|c|}{ Study population } & \multicolumn{2}{|c|}{ Methods } & \multicolumn{4}{|c|}{ Results } \\
\hline & $\mathbf{N}$ & Location & TB & $\begin{array}{l}\text { Median CD4+ } \\
\text { cells } / \mathrm{mm}^{3} \text { (IQR) }\end{array}$ & $\begin{array}{l}\text { Timing of ART } \\
\text { in weeks 'earlier' } \\
\text { vs 'later' }\end{array}$ & $\begin{array}{l}\text { Primary } \\
\text { endpoint }\end{array}$ & $\begin{array}{l}\text { Follow-up } \\
\text { in months }\end{array}$ & $\begin{array}{l}\text { Primary endpoint } \\
\text { 'earlier' vs 'later'a }\end{array}$ & $\begin{array}{l}\text { Primary endpoint } \\
\text { in CD4 }<50 \text { cells } /\left.\mu\right|^{b}\end{array}$ & $\begin{array}{l}\text { TB immune } \\
\text { reconstitution }\end{array}$ \\
\hline SAPIT [48] (first analysis) & 429 & South Africa & $\begin{array}{l}\text { Smear-positive } \\
\text { pulmonary TB }\end{array}$ & 150 (77 to 254$)$ & $\begin{array}{l}<12 \text { vs after end } \\
\text { TB treatment }\end{array}$ & Death & 12.1 & $\begin{array}{l}5.4 \text { vs } 12.1 \\
P=0.003^{c}\end{array}$ & Not reported & $\begin{array}{l}12.4 \% \text { vs } 3.8 \% \\
P<0.001\end{array}$ \\
\hline $\begin{array}{l}\text { SAPIT [96] (second } \\
\text { analysis) }\end{array}$ & 429 & South Africa & $\begin{array}{l}\text { Smear-positive } \\
\text { pulmonary TB }\end{array}$ & 150 (77 to 254$)$ & $\begin{array}{l}\text { Within } 4 \text { vs } 8 \\
\text { to } 12\end{array}$ & AIDS or death & 17.7 & $\begin{array}{l}6.9 \text { vs } 7.8 \\
P=0.73\end{array}$ & $\begin{array}{l}8.5 \text { vs } 26.3^{b} \\
P=0.06\end{array}$ & $\begin{array}{l}20.1 \% \text { vs } 7.7 \% \\
P<0.001\end{array}$ \\
\hline CAMELIA [95] & 660 & Cambodia & Smear-positive TB & 25 (11 to 56$)$ & 2 vs 8 & Death & 25 & $\begin{array}{l}18 \% \text { vs } 27 \% \\
P=0.006\end{array}$ & Not reported ${ }^{d}$ & $\begin{array}{l}33.1 \% \text { vs } 13.7 \% \\
P<0.001\end{array}$ \\
\hline STRIDE [55] & 809 & Multicontinent $\mathrm{e}^{\mathrm{e}}$ & $\begin{array}{l}\text { Confirmed or } \\
\text { presumed } \\
\text { pulmonary or } \\
\text { extrapulmonary TB }\end{array}$ & 77 (36 to 145) & 2 vs 8 to 12 & AIDS or death & 12 & $\begin{array}{l}12.9 \% \text { vs } 16.1 \% \\
P=0.45\end{array}$ & $\begin{array}{l}15.5 \% \text { vs } 26.6 \% \\
P=0.02\end{array}$ & $\begin{array}{l}11 \% \text { vs } 5 \% \\
P=0.02\end{array}$ \\
\hline TB Meningitis [97] & 253 & Vietnam & TB meningitis & 39 (18 to 116$)$ & $\leq 1$ vs 8 & Death $^{f}$ & 12 & $\begin{array}{l}59.8 \% \text { vs } 55.6 \% \\
P=0.50\end{array}$ & $\begin{array}{l}63.3 \% \text { vs } 65.1 \% \\
P=0.84\end{array}$ & Not reported \\
\hline TIME Trial [98] & 156 & Thailand & $\begin{array}{l}\text { Confirmed or } \\
\text { presumed } \\
\text { pulmonary or } \\
\text { extrapulmonary TB }\end{array}$ & 43 (37 to 106) & 4 vs 12 & Death & 96 weeks & $\begin{array}{l}7.6 \% \text { vs } 6.5 \% \\
P>0.99\end{array}$ & $\begin{array}{l}8.7 \% \text { vs } 13.1 \% \\
P=0.725\end{array}$ & $\begin{array}{l}8.86 \text { vs } 5.02 \\
P=0.069\end{array}$ \\
\hline
\end{tabular}

Footnotes:

${ }^{a}$ Presented either as cumulative incidence of primary endpoint in early vs. later arm (\%) or as events per 100 person-years.

${ }^{\mathrm{b}}$ Prespecified analysis.

'Significant difference in mortality observed in patients with either CD4 counts $<200$ cells $/ \mu \mathrm{l}$ or 200 to 500 cells $/ \mu \mathrm{l}$.

dower CD4 was not associated with an increased risk for the primary endpoint.

'North America, South America, Asia, Africa.

'Primary endpoint was all cause mortality at 9 months. 
Table 7 Shared side effects of antiretroviral therapy (ART) and antituberculosis drugs

\begin{tabular}{|c|c|c|}
\hline Adverse effects & Antiretroviral drugs & Antituberculosis drugs \\
\hline Gastrointestinal disturbance and/or pain & AZT, ddl, Pls & RIF, INH, PZA, ethionamide, PAS, clofazamine, linezolid \\
\hline Liver injury & NVP, EFV, PIs, NRTIs ${ }^{a}$ & $\begin{array}{l}\text { RIF, INH, PZA and many second line drugs including } \\
\text { ethionamide, fluoroquinolones, PAS }\end{array}$ \\
\hline Peripheral neuropathy & D4T, ddl & INH, ethionamide, terizidone/cycloserine, linezolid \\
\hline Neuropsychiatric & EFV & Terizidone/cycloserine, ethionamide, fluoroquinolones, INH \\
\hline Renal impairment & TDF & Aminoglycosides and capreomycin \\
\hline Rash & $N V P, E F V, A B C$ & $\begin{array}{l}\text { Rifampicin, INH, PZA, ethambutol, streptomycin and many } \\
\text { second line drugs including fluoroquinolones, PAS, clofazamine }\end{array}$ \\
\hline Blood dyscrasias & AZT, 3TC & Linezolid, rifabutin, INH, rifampicin \\
\hline Cardiac conduction abnormalities & Pls & Bedaquiline, fluoroquinolones, clofazamine \\
\hline Pancreatitis & D4T, ddl & Linezolid \\
\hline Lactic acidosis & D4T, ddl & Linezolid \\
\hline
\end{tabular}

3TC 2',3'-dideoxy-3'-thiacytidine, $A B C$ abacavir, AZT zidovudine, D4T stavudine, ddl didanosine, EFV efavirenz, INH isoniazid, NRTIs nucleoside reverse transcriptase inhibitors, NVP nevirapine, PAS para-aminosalicylic acid, PIs protease inhibitors, PZA pyrazinamide, RIF rifampicin, TDF tenofovir.

${ }^{a}$ NRTIs (especially D4T and ddl) can cause steatohepatitis.

Steven Johnson syndrome and toxic epidermal necrolysis, fixed drug eruption, lichenoid drug eruptions and acute generalized exanthematous pustulosis [114]. Cotrimoxazole, NVP, and to a lesser extent EFV, can also cause many of the same clinical presentations [102,115,116]. HIV coinfection was associated with a fivefold increased risk of rash or drug fever in one study [117] but small, non-significant increases in risk in others $[105,108]$. If a clinically significant rash develops, all potentially responsible drugs need to be interrupted and then a carefully monitored rechallenge of first-line TB drugs can be considered once the rash has resolved. In a cohort of mainly HIV-infected patients rechallenged following cutaneous reactions to TB drugs, 50\% developed reintroduction reactions but only a small minority were severe [118].

Renal dysfunction may be caused via different mechanisms in patients receiving tenofovir, RIF or aminoglycosides (used for MDR-TB). Tenofovir and aminoglycosides may both cause tubular cell toxicity at the level of the proximal renal tubules, whereas RIF infrequently causes a tubulointerstitial nephritis mediated by immune hypersensitivity. Case reports describe renal failure in patients receiving a combination of tenofovir and aminoglycosides, although cohort studies have not confirmed an increased risk [119]. The combination is best avoided when possible. In patients with significant renal dysfunction, Use of tenofovir should be avoided where possible and dosing of ethambutol, NRTI drugs, some quinolones (ofloxacin and levofloxacin) and certain other second-line antituberculosis drugs (including cycloserine, para-aminosalicylic acid, clofazamine and linezolid) needs to be adjusted.

\section{TB Immune reconstitution inflammatory syndrome (IRIS)}

Two major forms of TB immune reconstitution syndrome (TB-IRIS) are recognized and these are called paradoxical TB IRIS and unmasking TB-IRIS and case definitions have been published [120]. Paradoxical TBIRIS is an important cause of morbidity in patients known to have HIV-associated TB and occurs within the first weeks of ART $[120,121]$. The typical clinical course of paradoxical TB-IRIS is as follows. Initiation of TB treatment in a patient with HIV infection and newly diagnosed TB results in clinical stabilization or improvement. However, subsequent introduction of ART is accompanied by recurrence or exacerbation of TB symptoms with new or worsening clinical signs of TB that often have a marked inflammatory component $[120,121]$.

While seldom life-threatening, deaths due to paradoxical TB-IRIS have been described. Two major risk factors identified in observational studies [122-125] and in clinical trials $[55,95,126]$ are a low CD4 count prior to ART and a shorter interval between starting TB treatment and ART. There is no diagnostic test for TB-IRIS; the diagnosis is based on clinical presentation and exclusion of alternative diagnoses such as bacterial infection or drug resistant TB [120]. However, drug-resistant TB is not only in the differential diagnosis as an alternative cause of the clinical deterioration but may also be a risk factor for the development of paradoxical TB-IRIS [127].

The second major form of TB-IRIS is commonly referred to as 'unmasking' TB-IRIS. This occurs when active $\mathrm{TB}$ is present but remains undiagnosed at the time of starting ART [120,128]. Subsequent immune recovery triggers the overt symptomatic presentation of TB. In a proportion of cases, unusual inflammatory features may also develop and such cases are regarded as having 'unmasking' TB-IRIS. Risk of unmasking TB-IRIS is therefore directly related to the efficiency of the preART screening process and the resulting prevalence of undiagnosed disease. 
Both types of TB IRIS have a wide range of clinical features often with involvement of multiple organ systems, reflecting widespread dissemination of $M$. tuberculosis in those with profound immunosuppression. Common features include fever, recurrence of respiratory symptoms with worsening infiltrates on chest radiographs, enlargement of lymph nodes (often with suppuration), formation of tuberculous abscesses and serous effusions [120,121]. There are many case reports of unusual and diverse complications, including granulomatous nephritis with renal impairment, parotitis, epididymo-orchitis, granulomatous hepatitis, splenic enlargement and abscess formation, psoas abscess, peritonitis, ascites and intestinal involvement $[120,121]$. Neurological TB-IRIS is particularly severe, manifesting with tuberculomas, tuberculous abscesses, cerebral edema, meningitis and radiculomyelopathy $[99,129,130]$. Neurological TB IRIS has a much poorer outcome compared to other forms, with a mortality of $13 \%$ to $75 \%$ $[99,129,130]$.

In most cases, the onset of paradoxical TB-IRIS is within the first 4 weeks of ART (median 14 days (IQR, 8 to 23) in 1 series [127]) but can occur within a few days. The proportion of patients affected ranges widely from $0 \%$ to over $40 \%$ [120] and this may relate to differences in risk factors and case definitions. In a meta-analysis, the summary risk estimate was $15.7 \%$ [131]. Of these, $3.2 \%$ died, representing approximately 1 in 200 patients with HIV-associated TB who start ART. The median duration of TB-IRIS symptoms has been reported to be 2 to 3 months $[124,125]$ but a minority of cases have a protracted course which may last for more than 1 year $[120,124,132]$. Such protracted cases typically have persistent or recurrent suppurative lymphadenitis or abscess formation. However, the majority of cases have a favorable long-term outcome [133].

TB-IRIS is not an indication for stopping ART, although this should be considered in life-threatening cases such as those with cerebral edema and depressed level of consciousness or severe respiratory failure. In mild cases, no specific treatment is usually required; the patient should be treated symptomatically and counseled regarding the need to continue ART and TB treatment. Corticosteroids should be considered if symptoms are more significant. In a randomized placebo-controlled trial, prednisone used at a dose of $1.5 \mathrm{mg} / \mathrm{kg} /$ day for 2 weeks followed by $0.75 \mathrm{mg} / \mathrm{kg} /$ day for 2 weeks was associated with reduced morbidity (duration of hospitalization and need for therapeutic procedures) [134]. Symptom improvement was more rapid and there was no excess risk of other severe infections [134]. Although no mortality benefit was demonstrated, patients with immediately life-threatening TB-IRIS were not enrolled in view of ethical considerations. Indeed, most experts recommend steroid therapy for life-threatening TB-IRIS, especially IRIS involving the
CNS. A subgroup of patients in this trial (approximately one in five) relapsed after stopping prednisone and required a further and more prolonged course to control symptoms [134]. Similarly, in other settings, TB-IRIS has relapsed in up to $50 \%$ of patients after stopping steroids [133] and thus the duration of therapy must be tailored according to the clinical response.

Non-steroidal anti-inflammatory drugs (NSAIDs) have also been used in the treatment of TB IRIS although no clinical trial data exist to support their use. Other forms of immunomodulatory therapy such as thalidomide, azathioprine and tumor necrosis factor $\alpha$ blockers (such as adalumimab) have been used in cases refractory to steroid therapy with anecdotal reports of benefit [135]. In patients with suppurative lymphadenitis or abscesses, needle aspiration may provide a pus sample to exclude drug-resistant TB as well as bringing symptomatic relief.

There is no evidence base for pharmacological prevention of TB-IRIS. However, this needs to be considered in view of the recommendation within guidelines for early ART initiation in TB patients with advanced HIV [11]. Adjunctive immunomodulatory therapies might reduce the risk or severity of TB-IRIS in such patients. A randomized placebo-controlled trial of prednisone for prevention of TB-IRIS in high-risk patients (CD4 counts $<100$ cells $/ \mathrm{mm}^{3}$ starting ART within 30 days of TB treatment) is underway [136]. Until results from this trial are available corticosteroids cannot be recommended for prevention of TB IRIS with the exception of patients with TB of the CNS for whom adjunctive steroids form part of the standard of care [137]. However, in such patients, TB IRIS occurs in approximately $50 \%$ of patients with CNS TB starting ART despite receipt of corticosteroids [99].

Other agents that have been proposed for prevention of TB IRIS are vitamin D, statins and the C-C chemokine receptor type 5 (CCR5) blocker maraviroc [135]. Vitamin D has modulating effects on both the adaptive and innate immune responses [138,139]. Statins have anti-inflammatory properties and there is precedence for using these agents for autoimmune inflammatory disorders in an experimental model $[140,141]$. However, neither vitamin D nor statins have yet been tested in clinical studies. Maraviroc, however, was shown not to prevent IRIS in a placebo-controlled trial conducted in Mexico and South Africa [142].

\section{Management of HIV-associated MDR-TB}

The emergence of MDR-TB and extensively drug resistant TB (XDR-TB) has compounded the HIV-associated TB epidemic in resource-limited settings [5,143]. MDR-TB is caused by strains that are resistant to both rifampicin and isoniazid whereas XDR-TB strains are MDR-TB strains with additional resistance to any quinolone drug and any 
one of the second-line injectable aminoglycosides (amikacin, capreomycin or kanamycin). Much disease remains undiagnosed due to lack of laboratory capacity. However, increasing implementation of the Xpert MTB/RIF assay now provides the means for rapid screening for RIF resistance, although follow-on testing is then required to further characterize the full drug susceptibility pattern. This can be performed phenotypically through culturebased systems but is very slow. In 2008, WHO approved the use of line probe assays for the rapid molecular detection of drug resistance in smear-positive specimens or culture isolates [144] and a range of commercially available assays now offer the possibility of much more rapid diagnosis of both MDR-TB and XDR-TB [145]. However, line-probe assays can only be used where appropriate laboratory facilities and expertise exist as they are highly technically demanding and are well beyond the scope of most resource-limited settings apart from in specialized reference laboratories.

Worldwide, successful treatment of MDR-TB is achieved in only approximately $50 \%$ to $60 \%$ of patients $[146,147]$, but management is considerably more difficult in resourcelimited settings and especially in those with HIV coinfection due to late diagnosis with more frequent extrapulmonary dissemination, high risks of drug cotoxicity and IRIS, copathology and poor adherence with prolonged, toxic regimens. The WHO recommends that patients with confirmed MDR-TB should receive a regimen containing pyrazinamide together with at least four second-line drugs in the intensive phase that are likely to be effective, including a fluoroquinolone (using a later generation agent where possible), a parenteral agent (such as amikacin or kanamycin), ethionamide (or prothionamide) and either cycloserine or p-aminosalicylic acid (PAS) [13]. An intensive phase of 8 months and a total treatment duration of 20 months is suggested for most patients, but may be modified according to response. A range of other second-line drugs that have limited efficacy may be used for treatment of XDR-TB and treatment regimens should be based upon drug susceptibility testing [13]. However, evidence to inform best practice is lacking and outcomes are often poor.

Co-trimoxazole prophylaxis and ART are recommended for all patients with HIV-associated MDR-TB regardless of CD4 count and the timing of ART initiation is similar as for drug-susceptible TB [11]. Many of the second-line MDR-TB drugs are poorly tolerated and drug discontinuation rates are high as a result of adverse effects. MDR-TB may be a risk factor for TB IRIS in view of slow mycobacterial antigen clearance [127]. Nutritional depletion and co-morbid conditions may further undermine outcomes.

Adverse events are frequent in HIV-infected patients receiving MDR treatment, the most common being gastrointestinal symptoms, peripheral neuropathy, hypothyroidism, deafness, psychiatric symptoms and hypokalemia $[148,149]$. In up to $40 \%$ of patients these adverse events are severe [148]. This relates to the inherent toxicity associated with MDR drugs; it does not appear that HIV-infected patients experience a higher incidence of adverse events than HIV-uninfected patients, nor that coadministration with ART increases toxicity [148,150,151].

Antiretroviral drugs do share common toxicities with second-line antituberculosis drugs, however (Table 7). Some of the most challenging of these are neuropsychiatric side effects. EFV causes inattention, vivid dreams and dizziness in up to $50 \%$ of patients, but in a minority these can be severe with mood disturbance or psychosis. Cycloserine (or terizidone) is a well recognized cause of psychosis, seizures and other CNS side effects although several other drugs such as the quinolones, ethionamide and high dose isoniazid can also cause CNS side effects. If patients develop severe CNS side effects it may be necessary to withdraw all possible culprit drugs with careful sequential reintroduction once resolved. Cycloserine should probably be regarded as the most likely culprit for psychosis and seizures. Antipsychotic or antidepressant medications may be required. EFV should not be routinely avoided because the majority of MDR-TB patients tolerate it well.

Much research is needed on how to improve treatment for drug-resistant TB. A shortened MDR-TB regimen of 9 months, which was found to be effective and well tolerated in Bangladesh [152], is now being evaluated in Ethiopia, South Africa and Vietnam and includes patients with HIV-associated TB. In the future, the newly approved agent bedaquiline (TMC-207) as well as two new nitroimidazoles (PA-824 and delaminid (OPC67683) under evaluation) may offer the prospects of improved treatment for MDR-TB [38]. However, a prolonged timeline is needed to adequately define how to combine existing agents and new drugs in regimens that optimize outcomes and that can be combined with ART in those with HIVassociated TB.

\section{Conclusions}

The HIV-associated TB epidemic is a major challenge to international public health, remaining the most important opportunistic infection in people living with HIV globally and accounting for nearly 0.5 million deaths each year. However, over the past 10 years, major progress has been achieved in defining guidelines for the optimum case management with a combination of co-trimoxazole prophylaxis, optimally timed ART, and diagnosis and appropriate supportive care for treatment complications including drug toxicity and IRIS. The major remaining challenges are the management of $\mathrm{TB}$ in the increasing proportion of patients receiving 
PI-containing ART and the management of drug resistant TB. Having defined case management strategies, the ongoing challenge is to further develop effective, comprehensive and sustainable means of delivery through health systems.

\section{Abbreviations}

ALT: alanine transaminase; ART: antiretroviral treatment; CNS: central nervous system; CYP: cytochrome P450 enzyme; E: ethambutol; EFV: efavirenz; $\mathrm{H} / \mathrm{INH}$ : isoniazid; IRIS: immune reconstitution inflammatory syndrome; LAM: lipoarabinomannan; MDR-TB: multidrug resistant tuberculosis; NNRTI: non-nucleoside reverse transcriptase inhibitor; NVP: nevirapine; PI: protease inhibitor; PITC: provider initiated counseling and testing; R/RIF: rifampicin; TB: tuberculosis; VCT: voluntary counseling and testing; WHO: World Health Organization; XDR-TB: extensively drug resistant tuberculosis; Z: pyrazinamide.

\section{Competing interests}

The authors declare they have no competing interests.

\section{Authors' contributions}

The first draft was written by SDL, GM and HMcl. All authors contributed to the development of subsequent and final drafts. All authors approved the final version.

\section{Acknowledgments}

SDL is funded by the Wellcome Trust, London, UK

\section{Author details}

${ }^{1}$ Department of Clinical Research, Faculty of Infectious and Tropical Diseases, London School of Hygiene and Tropical Medicine, Keppel Street, London WC1E 7HT, UK. ${ }^{2}$ The Desmond Tutu HIV Centre, Institute for Infectious Disease and Molecular Medicine, Faculty of Health Sciences, University of Cape Town, Cape Town, South Africa. ${ }^{3}$ Department of Medicine, Faculty of Health Sciences, University of Cape Town, Cape Town, South Africa. ${ }^{4}$ Clinical Infectious Diseases Research Initiative, Institute of Infectious Disease and Molecular Medicine, University of Cape Town, Cape Town, South Africa. ${ }^{5}$ Division of Clinical Pharmacology, Department of Medicine, Faculty of Health Sciences, University of Cape Town, Cape Town, South Africa. ${ }^{6}$ International Union against Tuberculosis and Lung Disease (The Union), Paris, France.

Received: 3 September 2013 Accepted: 7 November 2013 Published: 02 Dec 2013

\section{References}

1. World Health Organization: Global Tuberculosis Control Report 2012. Geneva: World Health Organization; 2012.

2. Lawn SD, Churchyard G: Epidemiology of HIV-associated tuberculosis. Curr Opin HIV AIDS 2009, 4:325-333.

3. WHO/UNAIDS: Global HIV/AIDS Response. Epidemic Update and Health Sector Progress Towards Universal Access. Progress report 2011. http://www.unaids. org/en/media/unaids/contentassets/documents/unaidspublication/2011/ 20111130 UA_Report en.pdf. 2011.

4. Lawn SD, Zumla Al: Tuberculosis. Lancet 2011, 378:57-72.

5. Wells CD, Cegielski JP, Nelson LJ, Laserson KF, Holtz TH, Finlay A, Castro KG, Weyer K: HIV infection and multidrug-resistant tuberculosis: the perfect storm. J Infect Dis 2007, 196:S86-S107.

6. Abubakar I, Zignol M, Falzon D, Raviglione M, Ditiu L, Masham S, Adetifa I, Ford N, Cox H, Lawn SD, Marais BJ, McHugh TD, Mwaba P, Bates M, Lipman M, Zijenah L, Logan S, McNerney R, Zumla A, Sarda K, Nahid P, Hoelscher M, Pletschette M, Memish ZA, Kim P, Hafner R, Cole S, Migliori GB, Maeurer M, Schito M: Drug-resistant tuberculosis: time for visionary political leadership. Lancet Infect Dis 2013, 13:529-539.

7. De Cock KM, Chaisson RE: Will DOTS do it? A reappraisal of tuberculosis control in countries with high rates of HIV infection. Int I Tuberc Lung Dis 1999, 3:457-465

8. Harries AD, Zachariah R, Corbett EL, Lawn SD, Santos-Filho ET, Chimzizi R, Harrington M, Maher D, Williams BG, De Cock KM: The HIV-associated tuberculosis epidemic-when will we act? Lancet 2010, 375:1906-1919.
9. World Health Organization: Interim Policy on Collaborative TB/HIV activities. Who/ HTM/TB/2004.330 WHO/HTM/HIV/2004.1. Geneva, Switzerland: WHO; 2004.

10. World Health Organization: WHO Policy on Collaborative TB/HIV Activities. Guidelines for National Programmes and Stakeholders. Geneva, Switzerland: World Health Organization; 2012.

11. World Health Organization: Consolidated Guidelines on the Use of Antiretroviral Drugs for Treating and Preventing HIV Infection. Recommendations for a Public Health Approach, June 2013. Geneva, Switzerland: World Health Organization; 2013.

12. World Health Organization: Treatment of Tuberculosis: Guidelines - Fourth Edition. Geneva, Switzerland: World Health Organization; 2010.

13. World Health Organization: Guidelines for the Management of Drug-Resistant Tuberculosis: 2011 Update. Geneva, Switzerland: World Health Organization; 2011.

14. Lucas SB, Hounnou A, Peacock C, Beaumel A, Djomand G, N'Gbichi JM, Yeboue K, Honde M, Diomande M, Giordano C: The mortality and pathology of HIV infection in a west African city. AIDS 1993, 7:1569-1579.

15. Rana FS, Hawken MP, Mwachari C, Bhatt SM, Abdullah F, Ng'ang'a LW, Power C, Githui WA, Porter JD, Lucas SB: Autopsy study of HIV-1-positive and HIV-1-negative adult medical patients in Nairobi, Kenya. J Acquir Immune Defic Syndr 2000, 24:23-29.

16. Ansari NA, Kombe AH, Kenyon TA, Hone NM, Tappero JW, Nyirenda ST, Binkin NJ, Lucas SB: Pathology and causes of death in a group of 128 predominantly HIV-positive patients in Botswana, 1997-1998. Int J Tuberc Lung Dis 2002, 6:55-63.

17. Cohen T, Murray M, Wallengren K, Alvarez GG, Samuel EY, Wilson D: The prevalence and drug sensitivity of tuberculosis among patients dying in hospital in KwaZulu-Natal, South Africa: a postmortem study. PLoS Med 2010, 7:e1000296.

18. Reid MJ, Shah NS: Approaches to tuberculosis screening and diagnosis in people with HIV in resource-limited settings. Lancet Infect Dis 2009, 9:173-184.

19. World Health Organization: Improving the Diagnosis and Treatment of SmearNegative Pulmonary and Extra-Pulmonary Tuberculosis among Adults and Adolescents. Recommendations for HIV-Prevalent and Resource-Constrained Set tings. WHO/HTM/2007.379 \& WHO/HIV/2007.1. Geneva, Switzerland: World Health Organization; 2007.

20. Holtz TH, Kabera G, Mthiyane T, Zingoni T, Nadesan S, Ross D, Allen J, Chideya S, Sunpath H, Rustomjee R: Use of a WHO-recommended algorithm to reduce mortality in seriously ill patients with HIV infection and smear-negative pulmonary tuberculosis in South Africa: an observational cohort study. Lancet Infect Dis 2011, 11:533-540.

21. Wilson D, Nachega J, Morroni C, Chaisson R, Maartens G: Diagnosing smear-negative tuberculosis using case definitions and treatment response in HIV-infected adults. Int J Tuberc Lung Dis 2006, 10:31-38,

22. Lawn SD, Ayles H, Egwaga S, Williams B, Mukadi YD, Santos Filho ED Godfrey-Faussett P, Granich RM, Harries AD: Potential utility of empirical tuberculosis treatment for HIV-infected patients with advanced immunodeficiency in high TB-HIV burden settings. Int J Tuberc Lung Dis 2011 15:287-295.

23. Cain KP, McCarthy KD, Heilig CM, Monkongdee $P$, Tasaneeyapan T, Kanara N, Kimerling ME, Chheng P, Thai S, Sar B, Phanuphak P, Teeratakulpisarn N, Phanuphak N, Nguyen HD, Hoang TQ, Le HT, Varma J: An algorithm for tuberculosis screening and diagnosis in people with HIV. N Engl J Med 2010, 362:707-716

24. Lawn SD, Wood R: Tuberculosis in antiretroviral treatment services in resource-limited settings: addressing the challenges of screening and diagnosis. J Infect Dis 2011, 204:S1159-S1167.

25. Getahun H, Kittikraisak W, Heilig CM, Corbett EL, Ayles H, Cain KP, Grant AD, Churchyard GJ, Kimerling M, Shah S, Lawn SD, Wood R, Maartens G, Granich $\mathrm{R}$, Date AA, Varma J: Development of a standardized screening rule for tuberculosis in people living with HIV in resource-constrained settings: individual participant data meta-analysis of observational studies. PLOS Med 2011, 8:e1000391.

26. Lawn SD, Mwaba P, Bates M, Piatek A, Alexander H, Marais BJ, Cuevas LE, McHugh TD, Zijenah L, Kapata N, Abubakar I, McNerney R, Hoelscher M, Memish ZA, Migliori GB, Kim P, Maeurer M, Schito M, Zumla A: Advances in tuberculosis diagnostics: the Xpert MTB/RIF assay and future prospects for a point-of-care test. Lancet Infect Dis 2013, 13:349-361.

27. World Health Organization: Roadmap for Rolling out Xpert Mtb/Rif for Rapid Diagnosis of TB and MDR-TB. Geneva, Switzerland: World Health Organization; 2010 
28. Lawn SD: Point-of-care detection of lipoarabinomannan (LAM) in urine for diagnosis of HIV-associated tuberculosis: a state of the art review. BMC Infect Dis 2012, 12:103.

29. Lawn SD, Kerkhoff AD, Vogt M, Wood R: Diagnostic accuracy of a low-cost, urine antigen, point-of-care screening assay for HIV-associated pulmonary tuberculosis before antiretroviral therapy: a descriptive study. Lancet Infect Dis 2012, 12:201-209.

30. Peter JG, Theron G, Zyl-Smit R, Haripersad A, Mottay L, Kraus S, Binder A Meldau R, Hardy A, Dheda K: Diagnostic accuracy of a urine lipoarabinomannan strip-test for TB detection in HIV-infected hospitalised patients. Eur Respir J 2012, 40:1211-1220.

31. Lawn SD, Dheda K, Kerkhoff AD, Peter JG, Dorman S, Boehme CC, Nicol M: Determine TB-LAM lateral flow urine antigen assay for HIV-associated tuberculosis: recommendations on the design and reporting of clinical studies. BMC Infect Dis 2013, 13:407.

32. Lawn SD, Kerkhoff AD, Vogt M, Wood R: Clinical significance of lipoarabinomannan detection in urine using a low-cost point-of-care diagnostic assay for HIV-associated tuberculosis. AIDS 2012, 26:1635-1643.

33. World Health Organization/UNAIDS: Guidance on Provider-Initiated HIV Testing and Counselling in Health Facilities. Geneva, Switzerland: WHO/ UNIADS; 2007

34. Kumar AM, Gupta D, Gupta RS, Satyanarayana S, Wilson S, Zachariah R, Lawn SD, Harries AD: HIV testing in people with presumptive tuberculosis: time for implementation. Lancet Respir Med 2013, 1:7-9.

35. Jindani A, Nunn AJ, Enarson DA: Two 8-month regimens of chemotherapy for treatment of newly diagnosed pulmonary tuberculosis: international multicentre randomised trial. Lancet 2004, 364:1244-1251.

36. Menzies D, Benedetti A, Paydar A, Martin I, Royce S, Pai M, Vernon A, Lienhardt C, Burman W: Effect of duration and intermittency of rifampin on tuberculosis treatment outcomes: a systematic review and metaanalysis. PLOS Med 2009, 6:e1000146.

37. Menzies D, Benedetti A, Paydar A, Royce S, Madhukar P, Burman W, Vernon A, Lienhardt C: Standardized treatment of active tuberculosis in patients with previous treatment and/or with mono-resistance to isoniazid: a systematic review and meta-analysis. PLoS Med 2009, 6:e1000150.

38. Zumla A, Nahid P, Cole ST: Advances in the development of new tuberculosis drugs and treatment regimens. Nat Rev Drug Discov 2013, 12:388-404

39. Jindani A, et al: A Multicentre Randomized Clinical Trial to Evaluate High-dose Rifapentine with a Quinolone for Treatment of Pulmonary TB: The RIFAQUIN Trial. Atlanta, USA: Program and abstracts of the 20th Conference on Retroviruses and Opportunistic Infections; 2013. Abstract \#147LB

40. Wiktor SZ, Sassan-Morokro M, Grant AD, Abouya L, Karon JM, Maurice C, Djomand G, Ackah A, Domoua K, Kadio A, Yapi A, Combe P, Tossou O, Roels TH, Lackritz EM, Coulibaly D, De Cock KM, Coulibaly IM, Greenberg AE: Efficacy of trimethoprim-sulphamethoxazole prophylaxis to decrease morbidity and mortality in HIV-1-infected patients with tuberculosis in Abidjan, Cote d'Ivoire: a randomised controlled trial. Lancet 1999, 353:1469-1475.

41. Zachariah R, Spielmann MP, Chinji C, Gomani P, Arendt V, Hargreaves NJ, Salaniponi FM, Harries AD: Voluntary counselling, HIV testing and adjunctive co-trimoxazole reduces mortality in tuberculosis patients in Thyolo, Malawi. AIDS 2003, 17:1053-1061

42. Mwaungulu FB, Floyd S, Crampin AC, Kasimba S, Malema S, Kanyongoloka $H$, Harries AD, Glynn JR, Fine PE: Co-trimoxazole prophylaxis reduces mortality in human immunodeficiency virus-positive tuberculosis patients in Karonga District, Malawi. Bull World Health Organ 2004, 82:354-363.

43. Grimwade K, Sturm AW, Nunn AJ, Mbatha D, Zungu D, Gilks CF: Effectiveness of co-trimoxazole prophylaxis on mortality in adults with tuberculosis in rural South Africa. AIDS 2005, 19:163-168.

44. Nunn AJ, Mwaba P, Chintu C, Mwinga A, Darbyshire JH, Zumla A: Role of co-trimoxazole prophylaxis in reducing mortality in HIV infected adults being treated for tuberculosis: randomised clinical trial. BMJ 2008 337:a257.

45. Lowrance DW, Makombe S, Harries AD, Shiraishi RW, Hochgesang M, BerleGrasse J, Libamba E, Schouten E, Ellerbrock T, Kamoto K: A public health approach to rapid scale-up of antiretroviral treatment in Malawi during 2004-2006. J Acquir Immune Defic Syndr 2008, 49:287-293.

46. World Health Organization: The Global Plan to STOP TB 2011-2015. Geneva, Switzerland: World Health Organization; 2010.
47. Lawn SD, Kranzer K, Wood R: Antiretroviral therapy for control of the HIVassociated tuberculosis epidemic in resource-limited settings. Clin Chest Med 2009, 30:685-699.

48. Abdool Karim SS, Naidoo K, Grobler A, Padayatchi N, Baxter C, Gray A, Gengiah T, Nair G, Bamber S, Singh A, Khan M, Pienaar J, El-Sadr W, Friedland G, Abdool Karim Q: Timing of initiation of antiretroviral drugs during tuberculosis therapy. N Engl J Med 2010, 362:697-706.

49. hiv-druginteractions.org: Homepage. [http://www.hiv-druginteractions.org]

50. Cohen K, Grant A, Dandara C, Mcllleron H, Pemba L, Fielding K, Charalombous S, Churchyard G, Smith P, Maartens G: Effect of rifampicinbased antitubercular therapy and the cytochrome P450 2B6 516G>T polymorphism on efavirenz concentrations in adults in South Africa. Antivir Ther 2009, 14:687-695.

51. Uttayamakul S, Likanonsakul S, Manosuthi W, Wichukchinda N, Kalambaheti T, Nakayama EE, Shioda T, Khusmith S: Effects of CYP2B6 G516T polymorphisms on plasma efavirenz and nevirapine levels when co-administered with rifampicin in HIV/TB co-infected Thai adults. AIDS Res Ther 2010, 7:8

52. Ngaimisi E, Mugusi S, Minzi O, Sasi P, Riedel KD, Suda A, Ueda N, Janabi M, Mugusi F, Haefeli WE, Bertilsson L, Burhenne J, Aklillu E: Effect of rifampicin and CYP2B6 genotype on long-term efavirenz autoinduction and plasma exposure in HIV patients with or without tuberculosis. Clin Pharmacol Ther 2011, 90:406-413.

53. Luetkemeyer AF, Rosenkranz SL, Lu D, Marzan F, Ive P, Hogg E, Swindells S, Benson CA, Grinsztejn B, Sanne IM, Havlir DV, Aweeka F, Adult AIDS, Clinica Trials Group A5221 Study Team: Relationship between weight, efavirenz exposure, and virologic suppression in HIV-infected patients on rifampin-based tuberculosis treatment in the AIDS clinical trials group A5221 STRIDE study. Clin Infect Dis 2013, 57:586-593.

54. Boulle A, Van CG, Cohen K, Hilderbrand K, Mathee S, Abrahams M, Goemaere E, Coetzee D, Maartens G: Outcomes of nevirapine- and efavirenz-based antiretroviral therapy when coadministered with rifampicin-based antitubercular therapy. JAMA 2008, 300:530-539.

55. Havlir DV, Kendall MA, Ive P, Kumwenda J, Swindells S, Qasba SS, Luetkemeyer AF, Hogg E, Rooney JF, Wu X, Hosseinipour MC, Lalloo U, Veloso VG, Some FF, Kumarasamy N, Padayatchi N, Santos BR, Reid S, Hakim J, Mohapi L, Mugyenyi P, Sanchez J, Lama JR, Pape JW, Sanchez A, Asmelash A, Moko E, Sawe F, Andersen J, Sanne I, et al: Timing of antiretroviral therapy for HIV-1 infection and tuberculosis. N Engl J Med 2011, 365:1482-1491.

56. Bonnet M, Bhatt N, Baudin E, Silva C, Michon C, Taburet AM, Ciaffi L, Sobry A, Bastos R, Nunes E, Rouzioux C, Jani I, Calmy A, CARINEMO study group: Nevirapine versus efavirenz for patients co-infected with HIV and tuberculosis: a randomised non-inferiority trial. Lancet Infect Dis 2013, 13:303-312.

57. Lawn SD, Myer L, Bekker LG, Wood R: Burden of tuberculosis in an antiretroviral treatment programme in sub-Saharan Africa: impact on treatment outcomes and implications for tuberculosis control. AIDS 2006, 20:1605-1612

58. Puls R, The ENCORE1 Study Group: A daily dose of $400 \mathrm{mg}$ efavirenz (EFV) is non-inferior to the standard 600mg dose: week 48 data from the ENCORE1 study, a randomised, double-blind, placebo controlled, non-inferiority trial. Abstract WELBBO1. Kuala Lumpur, Malaysia: 7th International AIDS Society Conference on HIV Pathogenesis, Treatment and Prevention 2013, IAS 2013.

59. Federal Drug Administation (FDA): Sustiva labeling update/dosing adjustment with rifampin. [http://www.fda.gov/ForConsumers/ByAudience/ ForPatientAdvocates/HIVandAIDSActivities/ucm294476.htm].

60. Kwara A, Lartey M, Sagoe KW, Court MH: Paradoxically elevated efavirenz concentrations in HIV/tuberculosis-coinfected patients with CYP2B6 $516 \pi$ genotype on rifampin-containing antituberculous therapy. AIDS 2011, 25:388-390.

61. Mcllleron HM, Schomaker M, Ren $Y$, Sinxadi $P$, Nuttall JJ, Gous $H$, Moultrie $H$, Eley B, Merry C, Smith P, Haas DW, Maartens G: Effects of rifampin-based antituberculosis therapy on plasma efavirenz oncentrations in children vary by CYP2B6 genotype. AIDS 2013, 27:1933-1940.

62. Ramachandran G, Ramesh K, Hemanth Kumar AK, Jagan I, Vasantha M, Padmapriyadarsini C, Narendran G, Rajasekaran S, Swaminathan S: Association of high T allele frequency of CYP2B6 G516T polymorphism among ethnic south Indian HIV-infected patients with elevated plasma efavirenz and nevirapine. J Antimicrob Chemother 2009, 63:841-84.

63. Leger P, Dillingham R, Beauharnais CA, Kashuba AD, Rezk NL, Fitzgerald DW, Pape JW, Haas DW: CYP2B6 variants and plasma efavirenz concentrations 
during antiretroviral therapy in Port-au-Prince, Haiti. J Infect Dis 2009, 200:955-964.

64. Gulick RM, Ribaudo HJ, Shikuma CM, Lustgarten S, Squires KE, Meyer WA 3rd, Acosta EP, Schackman BR, Pilcher CD, Murphy RL, Maher WE, Witt MD, Reichman RC, Snyder S, Klingman KL, Kuritzkes DR, AIDS Clinical Trials Group Study A5095 Team: Triple-nucleoside regimens versus efavirenzcontaining regimens for the initial treatment of HIV-1 infection. $N$ Engl $J$ Med 2004, 350:1850-1861.

65. Srikantiah P, Walusimbi MN, Kayanja HK, Mayanja-Kizza H, Mugerwa RD, Lin R, Charlebois ED, Boom WH, Whalen CC, Havlir DV: Early virological response of zidovudine/lamivudine/abacavir for patients co-infected with HIV and tuberculosis in Uganda. AIDS 2007, 21:1972-1974.

66. Shao H, Crump J, Ramadhani H, Uiso L, Sendui-Nguyaine O, Kiwera R, et al: A randomised trial of early versus delayed fixed dose combination zidovudine/ lamivudine/abacavir in patients coinfected with HIV and tuberculosis: early findings of the tuberculosis and immune reconstitution syndrome trial. Abstract \#796.Denver, CO: Abstracts of the 13th Conference on Retroviruses and Opportunistic Infections; 2006.

67. Loeliger A, Suthar AB, Ripin D, Glaziou P, O'Brien M, Renaud-Thery F, Crowley S, Williams B, Ridzon R, Granich R, Gilks C: Protease inhibitor-containing antiretroviral treatment and tuberculosis: can rifabutin fill the breach? Int J Tuberc Lung Dis 2012, 16:6-15.

68. Veldkamp Al, Hoetelmans RM, Beijnen JH, Mulder JW, Meenhorst PL: Ritonavir enables combined therapy with rifampin and saquinavir. Clin Infect Dis 1999, 29:1586.

69. la Porte CJ, Colbers EP, Bertz R, Voncken DS, Wikstrom K, Boeree MJ, Koopmans PP, Hekster YA, Burger DM: Pharmacokinetics of adjusted-dose lopinavir-ritonavir combined with rifampin in healthy volunteers. Antimicrob Agents Chemother 2004, 48:1553-1560.

70. Rolla VC, Silva Vieira MA, Pereira PD, Lourenco MC, De Jesus CS, Goncalves MM, Ferreira FM, Werneck-Barroso E: Safety, efficacy and pharmacokinetics of ritonavir $400 \mathrm{mg} /$ saquinavir $400 \mathrm{mg}$ twice daily plus rifampicin combined therapy in HIV patients with tuberculosis. Clin Drug Investig 2006, 26:469-479.

71. Decloedt EH, Mcllleron H, Smith P, Merry C, Orrell C, Maartens G Pharmacokinetics of lopinavir in HIV-infected adults receiving rifampin with adjusted doses of lopinavir-ritonavir tablets. Antimicrob Agents Chemother 2011, 55:3195-3200

72. L'homme RF, Nijland HM, Gras L, Aarnoutse RE, van Crevel R, Boeree M, Brinkman $K$, Prins JM, Juttmann JR, Burger DM: Clinical experience with the combined use of lopinavir/ritonavir and rifampicin. AIDS 2009, 23:863-865.

73. Nijland HM, L'homme RF, Rongen GA, van Uden P, van Crevel R, Boeree MJ, Aarnoutse RE, Koopmans PP, Burger DM: High incidence of adverse events in healthy volunteers receiving rifampicin and adjusted doses of lopinavir/ritonavir tablets. AIDS 2008, 22:931-935.

74. Murphy RA, Marconi VC, Gandhi RT, Kuritzkes DR, Sunpath H: Coadministration of lopinavir/ritonavir and rifampicin in HIV and tuberculosis co-infected adults in South Africa. PLOS ONE 2012, 7:e44793.

75. Decloedt EH, Maartens G, Smith P, Merry C, Bango F, Mcllleron H: The safety, effectiveness and concentrations of adjusted lopinavir/ritonavir in HIV-infected adults on rifampicin-based antitubercular therapy. PLOS ONE 2012, 7:e32173.

76. Sant'Anna FM, Velasque L, Costa MJ, Schmaltz CA, Morgado MG, Lourenco MC, Grinsztejn B, Rolla VC: Effectiveness of highly active antiretroviral therapy (HAART) used concomitantly with rifampicin in patients with tuberculosis and AIDS. Braz J Infect Dis 2009, 13:362-366.

77. Singh R, Marshall N, Smith CJ, Reynolds CJ, Breen RA, Bhagani S, Cropley I, Hopkins S, Swaden L, Johnson MA, Lipman MC: No impact of rifamycin selection on tuberculosis treatment outcome in HIV coinfected patients. AIDS 2013, 27:481-484.

78. Matteelli A, Carvalho AC, Apostoli A, Tinelli C, Scudeller L, El Hamad I, Bonora S, Girardi E, Gori A, Mussini C: Completion Rate and Viro-Immunological Response to Combined TB/HIV Treatment: Results from the RIFART Study. [Abstract 854]. Atlanta, GA: Program and abstracts of the 20th Conference on Retroviruses and Opportunistic Infections; 2013.

79. Boulanger C, Hollender E, Farrell K, Stambaugh JJ, Maasen D, Ashkin D, Symes S, Espinoza LA, Rivero RO, Graham JJ, Peloquin CA: Pharmacokinetic evaluation of rifabutin in combination with lopinavir-ritonavir in patients with HIV infection and active tuberculosis. Clin Infect Dis 2009, 49:1305-1311.

80. Khachi $\mathrm{H}, \mathrm{O}^{\prime}$ Connell $\mathrm{R}$, Ladenheim D, Orkin C: Pharmacokinetic interactions between rifabutin and lopinavir/ritonavir in HIV-infected patients with mycobacterial co-infection. J Antimicrob Chemother 2009, 64:871-873.
81. Naiker S, Conolly C, Weisner L, Phillips D, Harries A, Lienhardt C, Mcllleron H, Pym A: Pharmacokinetic Evaluation of Different Rifabutin Dosing Strategies in African TB Patients on Lopinavir/ritonavir-based ART [abstract 650]. Boston, MA: Program and abstracts of the 18th Conference on Retroviruses and Opportunistic Infections; 2011.

82. Huy Dung N, Barrail-Tran A, Thi Ngoc Lan N, Hong Duc N, Thi Nguyet Thu N, Ngoc Lan N, Laureillard D, Thi Xuan Lien T, Borand L, Quillet C, Connolly C, Lagarde D, Pym A, Lienhardt C, Taburet A-M, Harries AD: Rifabutin Pharmacokinetics when Coadministered with Lopinavir/Ritonavir in HN-infected Patients with Tuberculosis in Vietnam: results of ANRS12150b Cross-over Clinical Trial [abstract WEPE470]. 7th IAS Conference on HN Pathogenesis and Treatment (Kuala Lumpur). Geneva, Switzerland: International AIDS Society; 2013.

83. Jenny-Avital ER, Joseph K: Rifamycin-resistant Mycobacterium tuberculosis in the highly active antiretroviral therapy era: a report of 3 relapses with acquired rifampin resistance following alternate-day rifabutin and boosted protease inhibitor therapy. Clin Infect Dis 2009, 48:1471-1474.

84. Weiner M, Benator D, Burman W, Peloquin CA, Khan A, Vernon A, Jones B, Silva-Trigo C, Zhao Z, Hodge T: Association between acquired rifamycin resistance and the pharmacokinetics of rifabutin and isoniazid among patients with HIV and tuberculosis. Clin Infect Dis 2005, 40:1481-1491.

85. Department of Health and Human Services, Panel on antiretroviral guidelines for adults and adolescents: Guidelines for the use of antiretroviral agents in HIV-1-infected adults and adolescents. [http://aidsinfo.nih.gov/ContentFiles/AdultandAdolescentGL.pdf]

86. Moultrie H, Mcllleron H, Sawry S, Kellermann T, Wiesner L, Kindra G, Gous H, Van Rie A: High Rate of Neutropenia in Young Children Receiving Concomitant Ribabutin and Lopinavir/Ritonavir [abstract 993]. Seattle, WA: Program and abstracts of the 19th Conference on Retroviruses and Opportunistic Infections; 2012.

87. Ng J, Nada A, Freeman S, Chiu YL, Cohen D, Bernstein B, Awni W, Klein C: Pharmacokinetics of RIFABUTIN 150 mg TIW plus Lopinavir/Ritonavir (LPV/r) 400/100 mg Bid Administered in Healthy Adult Subjects (abstract O_21). Amsterdam, The Netherlands: 10th International Workshop on Clinical Pharmacology of HIV Therapy; 2009.

88. Sekar V, Lavreys L, de CT V, Berckmans C, Spinosa-Guzman S, Vangeneugden T, De Pauw M, Hoetelmans R: Pharmacokinetics of darunavir/ritonavir and rifabutin coadministered in HIV-negative healthy volunteers. Antimicrob Agents Chemother 2010, 54:4440-4445.

89. Wenning LA, Hanley WD, Brainard DM, Petry AS, Ghosh K, Jin B, Mangin E, Marbury TC, Berg JK, Chodakewitz JA, Stone JA, Gottesdiener KM, Wagner JA, Iwamoto M: Effect of rifampin, a potent inducer of drug-metabolizing enzymes, on the pharmacokinetics of raltegravir. Antimicrob Agents Chemother 2009, 53:2852-2856.

90. Sauvageon H, Grinsztejn B, Arnold V, Veloso V, Vorsatz C, Pilotto JH, Grondin C, Chene G, Taburet A-M, Molina J-M: Pharmacokinetics of Two Doses of Raltegravir in Combination with Rifampin in HIV-TB co-infected Patients, an ANRS 12180 Reflate TB sub-study [abstract 539]. Atlanta, GA: Program and abstracts of the 20th Conference on Retroviruses and Opportunistic Infections; 2013.

91. Mena A, Vazquez P, Castro A, Lopez S, Bello L, Pedreira JD: Clinical experience of raltegravir-containing regimens in HIV-infected patients during rifampicin-containing treatment of tuberculosis. J Antimicrob Chemother 2011, 66:951-952.

92. Grinsztejn B, De Castro N, Arnold V, Veloso V, Pilotto JH, Brites C, Vorsatz C, Grondin C, Chene G, Molina J-M: Efficacy and Safety of Raltegravir vs Efavirenz for the Treatment of HIV/TB patients: 48-week Results of the ANRS 12180 Reflate TB Trial [abstract 853]. Atlanta, GA: Program and abstracts of the 20th Conference on Retroviruses and Opportunistic Infections; 2013.

93. Dooley KE, Sayre P, Borland J, Purdy E, Chen S, Song I, Peppercorn A, Everts S, Piscitelli S, Flexner C: Safety, tolerability, and pharmacokinetics of the HIV integrase inhibitor dolutegravir given twice daily with rifampin or once daily with rifabutin: results of a phase 1 study among healthy subjects. J Acquir Immune Defic Syndr 2013, 62:21-27.

94. Lawn SD, Torok ME, Wood R: Optimum time to start antiretroviral therapy during HIV-associated opportunistic infections. Curr Opin Infect Dis 2011, 24:34-42.

95. Blanc FX, Sok T, Laureillard D, Borand L, Rekacewicz C, Nerrienet E, Madec Y, Marcy O, Chan S, Prak N, Kim C, Lak KK, Hak C, Dim B, Sin Cl, Sun S, Guillard B, Sar B, Vong S, Fernandez M, Fox L, Delfraissy JF, Goldfeld AE, CAMELIA (ANRS 1295-CIPRA KH001) Study Team: Earlier versus later start of antiretroviral therapy in HIV-infected adults with tuberculosis. N Engl J Med 2011, 365:1471-1481. 
96. Abdool Karim SS, Naidoo K, Grobler A, Padayatchi N, Baxter C, Gray AL, Gengiah T, Gengiah S, Naidoo A, Jithoo N, Nair G, El-Sadr WM, Friedland G, Abdool Karim Q: Integration of antiretroviral therapy with tuberculosis treatment. N Engl J Med 2011, 365:1492-1501.

97. Török ME, Yen NT, Chau TT, Mai NT, Phu NH, Mai PP, Dung NT, Chau NV, Bang ND, Tien NA, Minh NH, Hien NQ, Thai PV, Dong DT, Anh do TT, Thoa NT, Hai NN, Lan NN, Lan NT, Quy HT, Dung NH, Hien TT, Chinh NT, Simmons CP, de Jong M, Wolbers M, Farrar JJ: Timing of initiation of antiretroviral therapy in human immunodeficiency virus (HIV)-associated tuberculous meningitis. Clin Infect Dis 2011, 52:1374-1383.

98. Manosuthi W, Mankatitham W, Lueangniyomkul A, Thongyen S, Likanonsakul S, Suwanvattana P, Thawornwan U, Suntisuklappon B, Nilkamhang S, Sungkanuparph S: Time to initiate antiretroviral therapy between 4 weeks and 12 weeks of tuberculosis treatment in HIVinfected patients: results from the TIME study. J Acquir Immune Defic Syndr 2012, 60:377-383.

99. Marais S, Meintjes G, Pepper DJ, Dodd LE, Schutz C, Ismail Z, Wilkinson KA, Wilkinson RJ: Frequency, severity, and prediction of tuberculous meningitis immune reconstitution inflammatory syndrome. Clin Infect Dis 2013, 56:450-460.

100. Saukkonen JJ, Cohn DL, Jasmer RM, Schenker S, Jereb JA, Nolan CM, Peloquin CA, Gordin FM, Nunes D, Strader DB, Bernardo J, Venkataramanan R, Sterling TR, ATS (American Thoracic Society) Hepatotoxicity of Antituberculosis Therapy Subcommittee: An official ATS statement: hepatotoxicity of antituberculosis therapy. Am J Respir Crit Care Med 2006, 174:935-952.

101. Montessori V, Press N, Harris M, Akagi L, Montaner JS: Adverse effects of antiretroviral therapy for HIV infection. CMAJ 2004, 170:229-238.

102. van Leth F, Phanuphak P, Ruxrungtham K, Baraldi E, Miller S, Gazzard B, Cahn P, Lalloo UG, van der Westhuizen IP, Malan DR, Johnson MA, Santos BR, Mulcahy F, Wood R, Levi GC, Reboredo G, Squires K, Cassetti I, Petit D, Raffi F, Katlama C, Murphy RL, Horban A, Dam JP, Hassink E, van Leeuwen R, Robinson P, Wit FW, Lange JM, 2NN Study team: Comparison of first-line antiretroviral therapy with regimens including nevirapine, efavirenz, or both drugs, plus stavudine and lamivudine: a randomised open-label trial, the 2NN Study. Lancet 2004, 363:1253-1263.

103. Lorent N, Sebatunzi O, Mukeshimana G, den EJ V, Clerinx J: Incidence and risk factors of serious adverse events during antituberculous treatment in Rwanda: a prospective cohort study. PLOS ONE 2011, 6:e19566.

104. Yimer G, Aderaye G, Amogne W, Makonnen E, Aklillu E, Lindquist L, Yamuah L, Feleke B, Aseffa A: Anti-tuberculosis therapy-induced hepatotoxicity among Ethiopian HIV-positive and negative patients. PLOS ONE 2008, 3:e1809.

105. Breen RA, Miller RF, Gorsuch T, Smith CJ, Schwenk A, Holmes W, Ballinger J, Swaden L, Johnson MA, Cropley I, Lipman MC: Adverse events and treatment interruption in tuberculosis patients with and without HIV co-infection. Thorax 2006, 61:791-794

106. Chaisson RE, Clermont HC, Holt EA, Cantave M, Johnson MP, Atkinson J, Davis H, Boulos R, Quinn TC, Halsey NA: Six-month supervised intermittent tuberculosis therapy in Haitian patients with and without HIV infection. Am J Respir Crit Care Med 1996, 154:1034-1038.

107. Perriens JH, St Louis ME, Mukadi YB, Brown C, Prignot J, Pouthier F, Portaels F, Willame JC, Mandala JK, Kaboto M, Ryder RW, Roscigno G, Piot P: Pulmonary tuberculosis in HIV-infected patients in Zaire. A controlled trial of treatment for either 6 or 12 months. N Engl J Med 1995, 332:779-784.

108. Marks DJ, Dheda K, Dawson R, Ainslie G, Miller RF: Adverse events to antituberculosis therapy: influence of HIV and antiretroviral drugs. Int J STD AIDS 2009, 20:339-345.

109. Hoffmann CJ, Charalambous S, Thio CL, Martin DJ, Pemba L, Fielding KL, Churchyard GJ, Chaisson RE, Grant AD: Hepatotoxicity in an African antiretroviral therapy cohort: the effect of tuberculosis and hepatitis B. AIDS 2007, 21:1301-1308.

110. Shipton LK, Wester CW, Stock S, Ndwapi N, Gaolathe T, Thior I, Avalos A, Moffat HJ, Mboya JJ, Widenfelt E, Essex M, Hughes MD, Shapiro RL: Safety and efficacy of nevirapine- and efavirenz-based antiretroviral treatment in adults treated for TB-HIV co-infection in Botswana. Int J Tuberc Lung Dis 2009, 13:360-366.

111. Kalyesubula R, Kagimu M, Opio KC, Kiguba R, Semitala CF, Schlech WF, Katabira ET: Hepatotoxicity from first line antiretroviral therapy: an experience from a resource limited setting. Afr Health Sci 2011, 11:16-23.
112. Sharma SK, Singla R, Sarda P, Mohan A, Makharia G, Jayaswal A, Sreenivas V, Singh S: Safety of 3 different reintroduction regimens of antituberculosis drugs after development of antituberculosis treatment-induced hepatotoxicity. Clin Infect Dis 2010, 50:833-839.

113. Schutz C, Ismail Z, Proxenos CJ, Marais S, Burton R, Kenyon C, Maartens G, Wilkinson RJ, Meintjes G: Burden of antituberculosis and antiretroviral drug-induced liver injury at a secondary hospital in South Africa. S Afr Med J 2012, 102:506-511.

114. Lehloenya RJ, Dheda K: Cutaneous adverse drug reactions to antituberculosis drugs: state of the art and into the future. Expert Rev Anti Infect Ther 2012, 10:475-486.

115. Toma E, Fournier S: Adverse reactions to co-trimoxazole in HIV infection. Lancet 1991, 338:954

116. Fagot JP, Mockenhaupt M, Bouwes-Bavinck JN, Naldi L, Viboud C, Roujeau JC: Nevirapine and the risk of Stevens-Johnson syndrome or toxic epidermal necrolysis. AIDS 2001, 15:1843-1848.

117. Yee D, Valiquette C, Pelletier M, Parisien I, Rocher I, Menzies D: Incidence of serious side effects from first-line antituberculosis drugs among patients treated for active tuberculosis. Am J Respir Crit Care Med 2003, 167:1472-1477.

118. Lehloenya RJ, Todd G, Badri M, Dheda K: Outcomes of reintroducing antituberculosis drugs following cutaneous adverse drug reactions. Int J Tuberc Lung Dis 2011, 15:1649-1657.

119. Kenyon C, Wearne N, Burton R, Meintjes G: The risks of concurrent treatment with tenofovir and aminoglycosides in patients with hivassociated tuberculosis. South Afr J HIV Med 2011, 12:43-45.

120. Meintjes G, Lawn SD, Scano F, Maartens G, French MA, Worodria W, Elliott $J H$, Murdoch D, Wilkinson RJ, Seyler C, John L, van der Loeff MS, Reiss P, Lynen L, Janoff EN, Gilks C, Colebunders R, International Network for the Study of HIV-associated IRIS: Tuberculosis-associated immune reconstitution inflammatory syndrome: case definitions for use in resource-limited settings. Lancet Infect Dis 2008, 8:516-523

121. Lawn SD, Bekker LG, Miller RF: Immune reconstitution disease associated with mycobacterial infections in HIV-infected individuals receiving antiretrovirals. Lancet Infect Dis 2005, 5:361-373.

122. Lawn SD, Myer L, Bekker LG, Wood R: Tuberculosis-associated immune reconstitution disease: incidence, risk factors and impact in an antiretroviral treatment service in South Africa. AIDS 2007, 21:335-341.

123. Breen RA, Smith CJ, Bettinson H, Dart S, Bannister B, Johnson MA, Lipman MC: Paradoxical reactions during tuberculosis treatment in patients with and without HIV co-infection. Thorax 2004, 59:704-707.

124. Burman W, Weis S, Vernon A, Khan A, Benator D, Jones B, Silva C, King B, LaHart C, Mangura B, Weiner M, El-Sadr W: Frequency, severity and duration of immune reconstitution events in HIV-related tuberculosis. Int J Tuberc Lung Dis 2007, 11:1282-1289.

125. Michailidis C, Pozniak AL, Mandalia S, Basnayake S, Nelson MR, Gazzard BG: Clinical characteristics of IRIS syndrome in patients with HIV and tuberculosis. Antivir Ther 2005, 10:417-422.

126. Naidoo K, Yende-Zuma N, Padayatchi N, Naidoo K, Jithoo N, Nair G, Bamber S, Gengiah S, El-Sadr WM, Friedland G, Abdool Karim S: The immune reconstitution inflammatory syndrome after antiretroviral therapy initiation in patients with tuberculosis: findings from the SAPIT trial. Ann Intern Med 2012, 157:313-324.

127. Meintjes G, Rangaka MX, Maartens G, Rebe K, Morroni C, Pepper DJ, Wilkinson KA, Wilkinson RJ: Novel relationship between tuberculosis immune reconstitution inflammatory syndrome and antitubercular drug resistance. Clin Infect Dis 2009, 48:667-676.

128. Lawn SD, Wilkinson RJ, Lipman MC, Wood R: Immune reconstitution and "unmasking" of tuberculosis during antiretroviral therapy. Am J Respir Crit Care Med 2008, 177:680-685.

129. Pepper DJ, Marais S, Maartens G, Rebe K, Morroni C, Rangaka MX, Oni T, Wilkinson RJ, Meintjes G: Neurologic manifestations of paradoxical tuberculosis-associated immune reconstitution inflammatory syndrome: a case series. Clin Infect Dis 2009, 48:e96-e107.

130. Agarwal U, Kumar A, Behera D, French MA, Price P: Tuberculosis associated immune reconstitution inflammatory syndrome in patients infected with HIV: meningitis a potentially life threatening manifestation. AIDS Res Ther 2012, 9:17.

131. Muller M, Wandel S, Colebunders R, Attia S, Furrer H, Egger M: Immune reconstitution inflammatory syndrome in patients starting antiretroviral therapy for HIV infection: a systematic review and meta-analysis. Lancet Infect Dis 2010, 10:251-261 
132. Olalla J, Pulido F, Rubio R, Costa MA, Monsalvo R, Palenque E, Costa JR, Del PA: Paradoxical responses in a cohort of HIV-1-infected patients with mycobacterial disease. Int J Tuberc Lung Dis 2002, 6:71-75.

133. Breton G, Bourgarit A, Pavy S, Bonnet D, Martinez V, Duval X, Longuet $P$, Abgrall S, Simon A, Leport C: Treatment for tuberculosis-associated immune reconstitution inflammatory syndrome in $34 \mathrm{HIV}$-infected patients. Int J Tuberc Lung Dis 2012, 16:1365-1370.

134. Meintjes G, Wilkinson RJ, Morroni C, Pepper DJ, Rebe K, Rangaka MX, Oni T, Maartens G: Randomized placebo-controlled trial of prednisone for paradoxical tuberculosis-associated immune reconstitution inflammatory syndrome. AIDS 2010, 24:2381-2390.

135. Lawn SD, Meintjes G: Pathogenesis and prevention of immune reconstitution disease during antiretroviral therapy. Expert Rev Anti Infect Ther 2011, 9:415-430.

136. Meintjes G, Schutz C: Preventing Tuberculosis-associated Immune Reconstitution Inflammatory Syndrome in High-risk Patients: a Randomized Placebo-controlled Trial of Prednisone (Pred-ART). [http://clinicaltrials.gov/ show/NCT01924286]

137. Thwaites GE, Nguyen DB, Nguyen HD, Hoang TQ, Do TT, Nguyen TC, Nguyen QH, Nguyen TT, Nguyen NH, Nguyen TN, Nguyen NL, Nguyen HD, Vu NT, Cao HH, Tran TH, Pham PM, Nguyen TD, Stepniewska K, White NJ, Tran TH, Farrar JJ: Dexamethasone for the treatment of tuberculous meningitis in adolescents and adults. N Engl J Med 2004, 351:1741-1751.

138. Baeke F, Takiishi T, Korf H, Gysemans C, Mathieu C: Vitamin D: modulator of the immune system. Curr Opin Pharmacol 2010, 10:482-496.

139. Conesa-Botella A, Meintjes G, Coussens AK, van der Plas H, Goliath R, Schutz C, Moreno-Reyes R, Mehta M, Martineau AR, Wilkinson RJ, Colebunders R, Wilkinson KA: Corticosteroid therapy, vitamin D status, and inflammatory cytokine profile in the HIV-tuberculosis immune reconstitution inflammatory syndrome. Clin Infect Dis 2012, 55:1004-1011.

140. Greenwood J, Steinman L, Zamvil SS: Statin therapy and autoimmune disease: from protein prenylation to immunomodulation. Nat Rev Immunol 2006, 6:358-370.

141. Sun HY, Singh N: Potential role of statins for the management of immune reconstitution syndrome. Med Hypotheses 2010.

142. Sierra-Madero J, Tierney A, Rassool M, Azzoni L, Sereti I, Andrade J, Mosqueda-Gomes L, Sanne I, Lederman M, CADRIS Study Team: Efficacy and Safety of Maraviroc to Prevent Immune Reconstitution Inflammatory Syndrome in High-risk Subjects Initiating ART: 24-Week Results of a Randomized, Placebocontrolled Trial. Altanta, GA: Program and Abstracts of the 20th Conference on Retroviruses and Opportunistic Infections; 2013.

143. Andrews JR, Shah NS, Gandhi N, Moll T, Friedland G: Multidrug-resistant and extensively drug-resistant tuberculosis: implications for the HIV epidemic and antiretroviral therapy rollout in South Africa. J Infect Dis 2007, 196:S482-S490.

144. World Health Organization: Molecular line probe assays for rapid screning of patients at risk of multidrug-resistant tuberculosis (MDR-TB). Policy statement June 2008. [http://www.who.int/tb/features_archive/ policy_statement.pdf] 2008.

145. Kalokhe AS, Shafiq M, Lee JC, Ray SM, Wang YF, Metchock B, Anderson AM, Nguyen ML: Multidrug-resistant tuberculosis drug susceptibility and molecular diagnostic testing. Am J Med Sci 2013, 345:143-148.

146. Ahuja SD, Ashkin D, Avendano M, Banerjee R, Bauer M, Bayona JN, Becerra MC, Benedetti A, Burgos M, Centis R, Chan ED, Chiang CY, Cox H, D'Ambrosio L, DeRiemer K, Dung NH, Enarson D, Falzon D, Flanagan K, Flood J, Garcia-Garcia ML, Gandhi N, Granich RM, Hollm-Delgado MG, Holtz $\mathrm{TH}$, Iseman MD, Jarlsberg LG, Keshavjee S, Kim HR, Koh WJ: Multidrug resistant pulmonary tuberculosis treatment regimens and patient outcomes: an individual patient data meta-analysis of 9,153 patients. PLoS Med 2012, 9:e1001300.

147. Orenstein EW, Basu S, Shah NS, Andrews JR, Friedland GH, Moll AP, Gandhi NR, Galvani AP: Treatment outcomes among patients with multidrugresistant tuberculosis: systematic review and meta-analysis. Lancet Infect Dis 2009, 9:153-161.

148. Isaakidis $P$, Varghese B, Mansoor H, Cox HS, Ladomirska J, Saranchuk P, Da Silva E, Khan S, Paryani R, Udwadia Z, Migliori GB, Sotgiu G, Reid T: Adverse events among HIV/MDR-TB co-infected patients receiving antiretroviral and second line anti-TB treatment in Mumbai. India. PLOS ONE 2012, 7:e40781.
149. Coyne KM, Pozniak AL, Lamorde M, Boffito M: Pharmacology of second-line antituberculosis drugs and potential for interactions with antiretroviral agents. AIDS 2009, 23:437-446.

150. Brust JC, Shah NS, van der Merwe TL, Bamber S, Ning Y, Heo M, Moll AP, Loveday M, Lalloo UG, Friedland GH, Gandhi NR: Adverse events in an integrated, home-based treatment program for MDR-TB and HIV in KwaZulu-Natal, South Africa. J Acquir Immune Defic Syndr 2012.

151. Arentz M, Pavlinac P, Kimerling ME, Horne DJ, Falzon D, Schunemann HJ, Royce S, Dheda K, Walson JL: Use of anti-retroviral therapy in tuberculosis patients on second-line anti-TB regimens: a systematic review. PLOS ONE 2012, 7:e47370.

152. Van Deun A, Maug AK, Salim MA, Das PK, Sarker MR, Daru P, Rieder HL: Short, highly effective, and inexpensive standardized treatment of multidrug-resistant tuberculosis. Am J Respir Crit Care Med 2010, 182:684-692.

10.1186/1741-7015-11-253

Cite this article as: Lawn et al:: Management of HIV-associated tuberculosis in resource-limited settings: a state-of-the-art review. BMC Medicine 2013, 11:253

\section{Submit your next manuscript to BioMed Central and take full advantage of:}

- Convenient online submission

- Thorough peer review

- No space constraints or color figure charges

- Immediate publication on acceptance

- Inclusion in PubMed, CAS, Scopus and Google Scholar

- Research which is freely available for redistribution

Submit your manuscript at www.biomedcentral.com/submit
C Biomed Central 